\begin{abstract}
UNIVERSIDADE DE SÃO PAULO
ESCOLA POLITÉCNICA

DEPARTAMENTO DE ENGENHARIA DE TELECOMUNICAÇÕES E CONTROLE
\end{abstract}

LUCAS GURGEL PRAXEDES

\title{
TÉCNICAS DE CONTROLE ESTOCÁSTICO EM POLÍTICA MONETÁRIA
}

São Paulo

2011 


\section{LUCAS GURGEL PRAXEDES}

\section{TÉCNICAS DE CONTROLE ESTOCÁSTICO EM POLÍTICA MONETÁRIA}

Dissertação apresentada ao Departamento de Engenharia de Telecomunicações e Controle da Universidade de São Paulo para obtenção do título de Mestre em Engenharia Elétrica.

Área de Concentração: Engenharia de Sistemas

Orientador: Prof. Dr. Oswaldo Luiz do Valle Costa

São Paulo

2011 
FICHA CATALOGRÁFICA

Praxedes, Lucas Gurgel

Técnicas de controle estocástico em política monetária / L.G. Praxedes. -- São Paulo, 2011.

$83 \mathrm{p}$.

Dissertação (Mestrado) - Escola Politécnica da Universidade de São Paulo. Departamento de Engenharia de Telecomunicações e Controle.

1. Controle estocásticos (Técnicas) 2. Política monetária I. Universidade de São Paulo. Escola Politécnica. Departamento de Engenharia de Telecomunicações e Controle II. t. 
UNIVERSIDADE DE SÃO PAULO

\section{FOLHA DE APROVAÇÃO}

\section{Técnicas de Controle Estocástico em Política Monetária}

\section{LUCAS GURGEL PRAXEDES}

Tese apresentada ao Departamento de Engenharia de Telecomunicações e Controle da Universidade de São Paulo para obtenção do título de Mestre em Engenharia Elétrica.

Área de Concentração: Engenharia de Sistemas

Banca Examinadora constituída por:

Ph. D. Oswaldo Luiz do Valle Costa - Orientador Universidade de São Paulo

Ph. D. Roberto Moura Sales

Universidade de São Paulo

Ph. D. Wanderlei Lima de Paulo

Universidade de São Paulo

São Paulo, 2011 


\section{Dedicatória}

Dedico este trabalho aos meus pais, por me apoiarem em minhas escolhas e me fazer acreditar na minha capacidade. 


\section{Agradecimentos}

Esta dissertação de mestrado é o resultado do meu trabalho nos dois últimos anos na Universidade de São Paulo (USP), onde cursei o mestrado em Engenharia de Sistemas. Pela oportunidade de vir para a USD desenvolver meu trabalho e por toda a orientação, eu agradeço especialmente ao Prof. Dr. Oswaldo Luiz do Valle Costa.

Também gostaria de agradecer ao Prof. Dr. Takashi Yoneyama pela orientação e pelas aulas sobre a Teoria de Controle Ótimo durante os dois anos de iniciação científica. Muito do conhecimento adquirido nessa época foi bastante útil para a conclusão deste trabalho. Agradeço também aos demais professores pelo conhecimento transmitido. 
"The scientist does not study nature because it is useful; he studies it because he delights in it, and he delights in it because it is beautiful. If nature were not beautiful, it would not be worth knowing, and if nature were not worth knowing, life would not be worth living."

Henri Poincaré 


\section{Resumo}

Este trabalho trata das aplicações da Teoria de Controle Ótimo ao problema de otimização da Política Monetária. Esse problema consiste em minimizar uma função que representa o custo da inflação para a sociedade, por meio de manipulações na variável de controle, que é a taxa de juros da economia. Serão considerados dois modelos para a dinâmica macroeconômica: um keynesiano e um novo-keynesiano. O problema de minimização sujeito à dinâmica keynesiana pode ser resolvido por meio dos conceitos tradicionais de controle ótimo, como o LQR e LQG. Por outro lado, o modelo novokeynesiano possuí uma dinâmica mais complexa e não-recursiva, impossibilitando a aplicação direta dos métodos de programação estocástica. Assim, o problema de minimização sujeito à essa dinâmica requer métodos mais complexos, como o método do Lagrangiano ou o método do ponto de sela recursivo. É apresentada a solução analítica para o problema de controle ótimo em cada tipo de dinâmica.

Em seguida, o problema de estimação de parâmetros é abordado. Métodos como o OLS e o GMM são empregados para estimar os parâmetros do modelo. Também são realizadas simulações para determinar numericamente as políticas de controle ótimo em alguns cenários. Por fim, a política monetária ótima é determinada para o período entre 2008 e 2009 e comparada com a política monetária adotada pelo governo.

Palavras-chave: Política Monetária, Controle Ótimo, Expectativas Racionais. 


\section{Abstract}

This article discusses the applications of the Optimal Control Theory to the Monetary Policy optimization problem. This problem consists in minimizing a function that represents the inflation cost to society, through manipulation on the control variable, which is the interest rate of the economy. It will be considered two models for macroeconomic dynamics: a Keynesian and a new-Keynesian model. The minimization problem subject to Keynesian dynamics can be solved through traditional optimal control tools, such as LQR and LQG. On the other hand, the second model has a more complex and non-recursive dynamic, precluding the direct application of stochastic programming methods. Thus, the minimization problem restricted to this dynamic requires more complex methods, like the Lagrangian or the recursive saddlepoint method. It is presented the analytical solution to the optimal control problem for each type of dynamics.

Then, the parameter estimation problem is addressed. Methods such as OLS and GMM are used to estimate the model parameters. Simulations are also carried out to determine numerically the optimal control policies in some scenarios. Finally, the optimal monetary policy is determined for the period between 2008 and 2009 and compared with the monetary policy adopted by the government.

Keywords: Monetary Policy, Optimal Control, Rational Expectations. 


\section{Lista de Figuras}

4.1 Hiato do Produto . . . . . . . . . . . . . . . . . . . . 2 23

4.2 PIB Potencial . . . . . . . . . . . . . . . . . . . 23

4.3 Comparação entre Algoritmos . . . . . . . . . . . . . . . 2 26

4.4 Comparação entre Métodos . . . . . . . . . . . . . . . . 26

4.5 Resultados do Modelo para a Curva IS . . . . . . . . . . . . 29

4.6 Resultados do Modelo para a Curva de Philips . . . . . . . . . . . . . 30

4.7 Resultados do Modelo para a Curva IS Antecipativa . . . . . . . . 32

4.8 Resultados do Modelo para a Curva de Philips Antecipativa . . . . . . 32 32

5.1 Exemplo de um controlador LQ . . . . . . . . . . . 36

5.2 Controlador LQG . . . . . . . . . . . . . . . . . . . . . . . . . 38

5.3 Controle Ótimo para os controladores LQG e LQR . . . . . . . . . 38

5.4 Controle Ótimo para os dois métodos apresentados . . . . . . . . . 54

6.1 Política Ótima no modelo keynesiano em função de R . . . . . . . . . . 58

6.2 Efeito do fator de desconto no controle ótimo . . . . . . . . . . 59

6.3 Resultado da simulação para o cenário de inflação inicial alta . . . . . . . . 60

6.4 Resultado da simulação para o cenário de inflação inicial baixa . . . . . . . 61 


\section{Lista de Tabelas}

2.1 Tipos de Política Monetária . . . . . . . . . . . . . 7

4.1 Teste da Raiz Unitária para a série do hiato do produto . . . . . . . . . . . 24

4.2 Parâmetros Estimados para o Modelo Keynesiano . . . . . . . . . . . . . 29

4.3 Parâmetros Estimados para o Modelo Novo-Keynesiano . . . . . . . . . . . 31 


\section{Sumário}

1 Introdução 1

1.1 Motivação . . . . . . . . . . . . . . . . . . . 1

1.2 Revisão da Literatura . . . . . . . . . . . . . . . . . . . . . . . 2 2

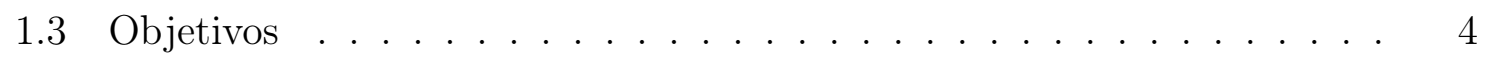

2 Principais Conceitos 6

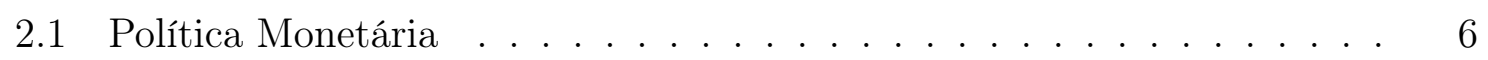

2.2 Política Monetária no Brasil . . . . . . . . . . . . . . . . 9

3 Modelos para a Dinâmica Macroeconômica 11

3.1 Resumo dos principais modelos . . . . . . . . . . . . . 11

3.2 Modelo Keynesiano . . . . . . . . . . . . . . . . . . . . . . . . 12

3.3 Modelo Novo-Keynesiano . . . . . . . . . . . . . . . . . . 15

4 Estimação de parâmetros $\quad 20$

4.1 Descrição do Problema . . . . . . . . . . . . . . . . . 20

4.2 Hiato do Produto . . . . . . . . . . . . . . . . . . 21

4.2.1 Filtro de Hodrick e Prescott . . . . . . . . . . . . . . 21

4.2.2 Método de Havey e Clark . . . . . . . . . . . . . . . 23

4.3 Estimação de Parâmetros . . . . . . . . . . . . . . . . . . . . . 26

4.3.1 Estimação para o modelo keynesiano . . . . . . . . . . . . 28

4.3.2 Estimação para o modelo novo-keynesiano . . . . . . . . . . . 30 
5 Problema de Controle Ótimo

5.1 Considerações Gerais . . . . . . . . . . . . . . . . . . . . . . 333

5.2 Controle Ótimo no modelo Keynesiano . . . . . . . . . . . . . . . . 34

5.2 .1 Formulação LQR . . . . . . . . . . . . . . . . . . . 34

5.2 .2 Formulação LQG . . . . . . . . . . . . . . . . . 35

5.3 Controle Ótimo no Modelo Novo Keynesiano . . . . . . . . . . . . . . . 38

5.3.1 Métodos de Solução para Modelos com Expectativas Racionais . 39

5.3.2 Política Ótima Simples ..................... 44

5.3 .3 Método do Lagrangeano . . . . . . . . . . . . . . 45

5.3.4 Método do Ponto de Sela Recursivo . . . . . . . . . . . . . . 50

6 Resultados das Simulações Numéricas

6.1 Introdução . . . . . . . . . . . . . . . . . . . . . . 555

6.2 Revisão dos modelos estimados . . . . . . . . . . . . 56

6.3 Revisão da função custo . . . . . . . . . . . . . . . . . . . . 57

6.4 Análise de cenários para condições iniciais . . . . . . . . . . . . 59

6.5 Comparação entre a política ótima e a política implementada no Brasil 61

7 Conclusão 63

A Calculo Matricial 66

B Passos intermediários em equações 67

B.1 Condições de Primeira ordem da equação 5.34 . . . . . . . . . . . . 67

Referências Bibliográficas $\quad 68$ 


\section{Capítulo 1}

\section{Introdução}

\subsection{Motivação}

O trabalho pioneiro de Arnold Tustin mostrou as possibilidades de aplicação da Teoria de Controle às outras ciências, desde a biologia até a economia. Em seu livro, Tustin (1953), é apresentada uma visão inovadora da teoria econômica por meio da aplicação dos conceitos de Controle, como realimentação de estados, estabilidade e controlabilidade de sistemas e regulação de variáveis.

De fato, muitos problemas em Economia são dinâmicos: as políticas e ações dos agentes econômicos, juntamente com os choques externos, movem a economia de um estado para outro. Além disso, esses problemas são também estocásticos: há incertezas sobre o estado atual da economia, sobre eventos futuros e quanto ao efeito das políticas. Por isso, o trabalho de Tustin foi seguido por muitos outros, explorando novas possibilidades de aplicação da Teoria de Controle.

Neste trabalho será abordado o problema de estabilização macroeconômica, no qual as variáveis geralmente analisadas são o consumo, desemprego, gastos do governo, exportações, importações, inflação, entre outros. Assim, para contornar choques indese-

jados na economia, o governo efetua ajustes em políticas com a esperança de estabilizar a economia. Esses ajustes são implementados por dois tipos de estratégias governamentais: a política fiscal e a política monetária. 
A política fiscal se refere aos gastos do governo, os quais são aprovados anualmente via processo legislativo. Já a política monetária se refere ao controle da oferta de dinheiro, com o intuito de expandir ou restringir as operações de crédito. Ao contrário da política fiscal, a política monetária não necessita de aprovação do órgão legislativo, e é executada de forma discricionária pelo governo. Assim, a implementação da política monetária é muito mais rápida, o que a torna bastante útil para anular os choques externos à economia. Por esse motivo, essa política será o foco deste trabalho.

O objetivo final da política monetária está relacionado ao controle da inflação, cuja importância é mostrada pela experiência internacional: segundo Woodford (2003), os países que mais cresceram nos últimos 20 anos foram aqueles que mantiveram taxas baixas de inflação. Assim, manter a inflação sob controle é condição necessária para o crescimento econômico e para o avanço das políticas sociais, porquanto as camadas mais pobres da população sofrem mais os efeitos negativos da inflação.

Em resumo, além de aumentar o horizonte de previsibilidade dos agentes econômicos, reduzir a incerteza e favorecer os investimentos, a queda da inflação favorece a preservação do poder de compra dos salários e contribui para a melhora na distribuição de renda, na medida em que sustenta a demanda agregada e assegura um maior crescimento ao longo do tempo.

\subsection{Revisão da Literatura}

Após o livro de Tustin (1953), surgiram muitos trabalhos sobre aplicações da teoria de controle em problemas de economia, dentre os quais se destaca o artigo de Pindyck (1973), que aborda o problema da política monetária ótima. Este artigo apresenta um modelo linear e invariante no tempo para a dinâmica macroeconômica e uma função custo quadrática, propondo uma solução para a política monetária que minimiza a função custo. Esse problema foi resolvido pelo Princípio do Mínimo de Pontryagin, bem como foram obtidas soluções numéricas para alguns casos.

Em contraposição, o artigo de Lucas (1976) propôs uma crítica à forma de aplica- 
ção da teoria controle ótimo, pois o anúncio de uma política ótima faria com que o comportamento dos agentes mudassem e, em consequência, os parâmetros do modelo também mudariam.

Uma resposta à critica de Lucas foi a formulação da política monetária como um jogo entre a autoridade monetária e os agentes econômicos. Assim, surgiram os modelos de equilíbrio conhecidos como DSGE ("Dynamic Stochastic General Equilibrium"), o qual assume que cada agente econômico faz uma escolha ótima levando em consideração as estratégias dos outros agentes, tanto no presente quanto no futuro. Pela soma as decisões de todos os agentes, é possível encontrar o ponto em que os preços dos ativos se equilibra (oferta e demanda).

Um marco no desenvolvimento dos modelos DSGE é o artigo de Blanchard e Kahn (1980), que desenvolve a formulação matemática para permitir a simulação de modelos com expectativas racionais, e o artigo de Kydland e Prescott (1982), que apresenta um modelo pequeno e coerente para a dinâmica da economia.

Esses modelos DSGE, por incorporarem as expectativas para o futuro na sua dinâmica, trouxeram grandes desafios para a área de otimização, os quais começaram a ser tratados com os trabalhos de Oudiz e Sachs (1984), Backus e Driffill (1986) e Levine e Currie (1987). Esses dois últimos trabalhos apresentam a solução para o problema de otimização da política monetária pela utilização de regras simples de realimentação de estados. Seguindo a mesma linha, na literatura brasileira pode-se citar o artigo de Bonomo e Brito (2001).

Trabalhos mais atuais, como Rotemberg e Woodford (1998), Soderlind (1999), Ljungqvist e Sargent (2000), Orphanides e Wieland (2000) e Sims (2002), apresentam métodos mais gerais para a obtenção da política monetária ótima, sem se restringir à realimentação de estados. Porém, atualmente, as pesquisas voltam-se para o estudo de modelos com saltos markovianos, como em Svensson e Williams (2005), Moessner (2006) e Svensson e Williams (2008), o que permite contornar a limitação dos modelos com parâmetros constantes. 


\subsection{Objetivos}

O problema dos formuladores da política monetária consiste em determinar a taxa de juros da economia que mantém a inflação dentro dos patamares aceitáveis. Entretanto, essa taxa não pode ser muito alta, pois há o risco de levar a economia à recessão, nem muito baixa, na medida em que pode não ser suficiente para garantir que a inflação esteja dentro da meta, conforme mostrado em Blanchard e Fischer (1989). Nesse tipo de dilema, as técnicas de controle podem fornecer o suporte teórico para solucionar esse problema.

Assim, o objetivo primário do trabalho é a determinação da política monetária ótima. Para alcançar esse objetivo, pode-se elencar uma série de passos intermediários que envolvem uma complexidade considerável:

- Modelagem: Estudo de modelos para descrever a dinâmica econômica para o problema de política monetária e das ferramentas para encontrar a solução ótima. Em geral, os modelos não permitem a aplicação direta dos métodos de programação dinâmica. Assim, existe uma série de transformações de variáveis e hipóteses adicionais que devem ser empregadas para encontrar o controle ótimo;

- Estimação: Para que seja possível realizar simulações numéricas, é necessário estimar os parâmetros do modelo usando as séries temporais disponíveis. A dificuldade é a presença de variáveis não observáveis no modelo e a persistência de choques externos nas séries temporais;

- Simulação: Uma vez que as políticas de controle estão definidas analiticamente e os parâmetros do modelo foram estimados, o passo final consiste em simular numericamente as leis de controle para um conjunto de condições iniciais diferentes. Isso permite avaliar se a política monetária empregada no Brasil está próxima ou distante da política ótima.

Dessa forma, este trabalho se organiza segundo a seguinte estrutura: 
- Capítulo 2 Apresenta um resumo dos conceitos de política monetária, focando principalmente no regime de metas para inflação, que é o regime monetário empregado no Brasil e em vários outros países;

- Capítulo 3: Define os modelos dinâmicos que serão utilizados neste trabalho. Começa pelo modelo Keynesiano, que foi bastante empregado durante muito tempo mas apresenta falhas conforme apontado pela hipótese das expectativas racionais. Em seguida, é apresentado o modelo novo Keynesiano, o qual apresenta uma dinâmica diferente, marcado pela presença de expectativas entre as variáveis;

- Capítulo 4. Resume o problema de estimação de parâmetros e detalha as ferramentas utilizadas para estimar os parâmetros dos modelos empregados nesse trabalho. Inicialmente, são apresentados métodos para estimar as variáveis não observáveis do modelo. Em seguida é apresentado o método mais comum de estimação de parâmetros: o OLS ("ordinary least squares"). Também é apresentado o GMM ("generalized method of moments");

- Capítulo 5 Mostra a estrutura do problema de controle ótimo e as ferramentes utilizadas na solução. Para o modelo keynesiano é utilizada a formulação LQR ("linear-quadratic-regulator") e LQG ("linear-quadratic-gaussian") para a determinação do controle ótimo. Já para o modelo novo keynesiano, é apresentado o método do Lagrangeano e o método do ponto de sela recursivo;

- Capítulo 6. Detalha os resultados obtidos nas simulações numéricas. A política monetária ótima é comparada com a política utilizada no período entre 2008 e 2009 no Brasil. 


\section{Capítulo 2}

\section{Principais Conceitos}

\subsection{Política Monetária}

O termo Politica Monetária se refere às ações tomadas por um banco central para influenciar a disponibilidade e o custo do dinheiro e do crédito, com o objetivo de ajudar a promover as metas econômicas nacionais e garantir a estabilidade da economia.

Existe uma relação entre as taxas de juros, ou custo de empréstimo, e a oferta de dinheiro. Segundo a lógica da oferta e demanda, com uma oferta maior de dinheiro, as taxas de juros caem. Como o banco central possui o monopólio da emissão de moeda, pode controlar a oferta de dinheiro para influenciar as taxas de juros da economia e, consequentemente, o crescimento econômico, inflação, taxa de câmbio, desemprego e outras variáveis.

Uma política é expansionista quando são tomadas medidas para aumentar a oferta de dinheiro, e reduzir as taxas de juros. Isso incentiva as pessoas e empresas a tomarem dinheiro emprestado para realizarem investimentos em aumento da produção ou em novos negócios. Esses investimentos possivelmente possuíam uma taxa de retorno que era inferior ao custo de financiamento, mas que se tornam viáveis quando o custo de financiamento é reduzido.

Por outro lado, diz-se que a política é restritiva (ou contracionista), quando o banco central reduz a oferta de dinheiro e, por consequência, as taxas de juros se elevam. Isso 
faz com que as empresas e pessoas mantenham apenas os investimentos mais rentáveis, adiando os demais projetos.

A política monetária também pode ser classificada em regimes monetários, de acordo com o método empregado para executar a política. A tabela 2.1 mostra três dos mais importantes regimes monetários.

\begin{tabular}{|c|c|c|}
\hline Política Monetátia & Variável de Mercado & Objetivo de Longo Prazo \\
\hline Metas de Inflação & Taxa de juros & Taxa de inflação constante \\
Taxa de Câmbio Fixa & Taxa de câmbio & Controlar a taxa câmbio \\
Padrão Ouro & Preço do ouro & Inflação baixa \\
\hline
\end{tabular}

Tabela 2.1: Tipos de Política Monetária

O padrão ouro foi adotado amplamente no século XIX e consistia na obrigação dos bancos converterem o papel-moeda em ouro. Assim, a quantidade de moeda em circulação era definida pelo estoque de ouro. Países com superávit na balança comercial (exportação maior que a importação) ficavam com o estoque de ouro crescente, o que aumentava a quantidade de dinheiro em circulação, resultando num aumento dos preços e redução da competitividade das exportações.

Dessa forma, o comércio entre países se ajustava de modo autônomo e gerava uma boa estabilidade ao sistema. Entretanto, o padrão ouro teve que ser abandonado em boa parte dos países da Europa no início do século XX, uma vez que estes precisavam emitir mais dinheiro para financiar a corrida armamentista da época. Esse fato contribuiu para o início de um período de formação de bolhas em ativos reais, hiperinflação e profundos desequilíbrios no comércio global, que atingiu seu ápice em 1929.

Após o período de guerras, em julho de 1944, na conferência de Bretton Woods, decidiu-se resgatar o padrão ouro na forma da conversibilidade entre o ouro e o dólar. Como as demais moedas tinham uma taxa de câmbio fixa para o dólar, implicitamente todas as moedas tinham um valor fixo em ouro. Esse acordo durou até 1971, quando a necessidade de financiar a Guerra do Vietnã e a persistência de déficits na balança comercial americana forçaram o término do acordo.

Com o fim do sistema de Breton Woods, o padrão ouro foi definitivamente aban- 
donado, mas o regime de taxas cambial fixa se manteve principalmente nos países emergentes. Nesse tipo de regime, o banco central precisa controlar a oferta de dinheiro para manter a taxa de câmbio no valor desejado. Entretanto, a eficácia desse modelo depende de um volume grande de reservas cambiais para que o mercado tenha confiança que o banco central conseguirá controlar o câmbio.

Em momentos de crise, os investidores procuram se desfazer da moeda local e comprar dólares. Por isso, o banco central precisa intervir, vendendo dólares para equilibrar o preço do câmbio. Entretanto, um país não pode emitir moeda estrangeira para continuar intervindo no câmbio. Assim, quando as reservas caem a um nível baixo, não há nada a fazer senão desvalorizar a moeda local. Quando o movimento é na direção contrária, com a moeda local se valorizando, o banco central pode, em teoria, imprimir quantidades infinitas de papel moeda usá-las para comprar dólar, reduzindo a valorização da moeda local.

O regime de taxa de câmbio fixa foi bastante comum entre os países emergentes, que mantinham suas moedas artificialmente valorizadas para controlar a inflação. O regime começou a ruir com a crise na Tailândia em 1997, provocado entre outras coisas pela combinação de altas taxas de juros e uma taxa de câmbio fixa, o que tornou a Tailândia e demais países da região uma região muito atrativa para os fluxos de capital. Assim, o crédito se expandiu enormemente e os preços de ativos atingiram valores insustentáveis.

Quando o fluxo de capitais para a Ásia começou a ser reduzido e o crédito disponível ficou limitado, os preços dos ativos começaram a cair, fazendo com que empresas e famílias interrompessem o pagamento dos empréstimos. Isso começou a gerar pânico entre investidores e houve uma fuga de capital em massa da região, o que contribuiu para piorar ainda mais a situação. As reservas cambiais se esgotaram, e a Tailândia foi o primeiro país da região a abandonar a taxa de câmbio fixa, em julho de 1997. Em pouco tempo, o mesmo processo ocorreu nos demais países da região, como Indonésia, Filipinas e Malásia. Em 1998, é a vez da Rússia sofrer uma grave crise e abandonar o regime de cambio fixo. Na América Latina, o Brasil abandonou esse regime em 1999 e 
a Argentina em 2002.

Atualmente, entre as maiores economias, apenas China e Arábia Saudita mantêm um regime de taxa de câmbio fixa, enquanto os demais adotam o regime de Metas de Inflação, com o câmbio flutuante. Nesse caso, há uma meta de inflação a ser cumprida e o banco central é responsável por determinar as taxas de juros necessárias para garantir o cumprimento da meta. As taxas de juros são revisadas periodicamente, em resposta a vários indicadores econômicos em uma tentativa de prever tendências e manter a inflação dentro da meta. O primeiro país a adotar esse regime foi a Nova Zelândia em 1990, e o pioneiro na implantação desse regime na América Latina foi o Chile em 1991.

\subsection{Política Monetária no Brasil}

Com a criação do Plano Real em 1995, o governo brasileiro decidiu manter o regime de câmbio fixo como meio de controlar a inflação brasileira. Essa taxa de câmbio fixa, juntamente com a abertura do mercado brasileiro ao comércio internacional, atrelava a inflação local à americana. Além disso, o câmbio supervalorizado tornava as importações baratas, o que contribuía para reduzir pressões inflacionárias locais. Adicionando a isso, as taxas de juros eram mantidas em um patamar alto, para incentivar o fluxo de capitais ao país e reduzir o potencial aparecimento da inflação de consumo.

Esse método alcançou grande sucesso no controle da inflação durante os primeiros anos. Entretanto, o modelo de câmbio supervalorizado e altas taxas de juros acabou provocando também um processo de desindustrialização e profundos desequilíbrios na balança comercial. Assim, as crises da Ásia em 1997 e da Rússia em 1998 acabaram por gerar uma crise de confiança no país, o que resultou na saída de capitais e num ataque especulativo contra a moeda. O Banco Central procurou conter esses fluxos até o esgotamento das reservas cambiais, quando foi forçado a desvalorizar a moeda.

Assim, em janeiro de 1999, o Brasil migrou para o modelo de câmbio flutuante, em um difícil período de transição onde o presidente do Banco Central foi substituído duas vezes. Pouco mais tarde, em junho de 1999, o país adotou formalmente o regime 
de metas para inflação. Segundo esse modelo, as metas de inflação são definidas pelo Conselho Monetário Nacional (CMN) e cabe ao Banco Central a missão de assegurar que a inflação siga a trajetória estabelecida pelo Conselho.

O controle da inflação é feito de forma indireta, por meio do anúncio da meta da taxa de juros, denominada de taxa Selic. Essa taxa é determinada pelo Comitê de Política Monetária (Copom), e o Banco Central é responsável por controlar a oferta de moeda necessária para manter os juros no nível desejado. Existe um conjunto de detalhes sobre o funcionamento do sistema de metas de inflação, conforme apresentado em Simonsen e Cysne (2007). 


\section{Capítulo 3}

\section{Modelos para a Dinâmica}

\section{Macroeconômica}

\subsection{Resumo dos principais modelos}

Este capítulo trata sobre os modelos dinâmicos que buscam quantificar os efeitos da Política Monetária na economia. Para tanto, mostra-se duas classes de modelos, com suas respectivas vantagens e desvantagens. Esses modelos servirão de base para a determinação da Política Monetária ótima no capítulo 5 , permitindo uma comparação entre os resultados obtidos para cada tipo de modelo.

Em ordem cronológica, a primeira classe de modelo macroeconômico deriva da teoria Keynesiana, que apresenta modelos recursivos para representar a dinâmica econômica. Em outras palavras, esse tipo de modelo é usado para estimar o estado futuro da economia dado o estado atual ou estados passados. Na seção 3.2 será apresentado a formulação geral desses modelos e o modelo simplificado que será utilizado para as simulações numéricas.

Apesar desses modelos se adequarem bem aos dados, eles foram contestados pelas novas teorias macroeconômicas. Assim, os trabalhos de Muth (1961), Lucas (1976), Sargent e Wallace (1974) iniciam uma nova formulação para a macroeconomia, com 
uma base teórica aceita até hoje. Essa teoria se embasa na otimização do comportamento dos agentes econômicos e um dos modelos dela derivados é o novo-keynesianos, apresentado na seção 3.3 .

Neste trabalho, o interesse será por modelos lineares desses dois grupos. Apesar da primeira classe de modelos ter sido comprometida pelas novas teorias econômicas, o objetivo é verificar se as políticas de controle ótimo se assemelham nas duas classes. Independentemente da forma do modelo, as variáveis consideradas serão as mesmas, a saber:

- Inflação $\pi_{t}$ : definida como a variação percentual em um determinado índice de preços;

- Hiato do produto $h_{t}$ : definido como a diferença entre o produto (PIB) e o produto potencial, que seria obtido com o pleno emprego dos fatores de produção.

\subsection{Modelo Keynesiano}

Os economistas da escola keynesiana argumentam que as decisões do setor privado resultam em uma alocação de recursos ineficiente, e que cabe ao setor público, por meio das políticas monetária e fiscal, corrigir essas falhas de mercado. Esse pensamento está resumido no trabalho de Modigliani (1977): "a private enterprise economy using an intangible money needs to be stabilized, can be stabilized, and therefore should be stabilized by appropriate monetary and fiscal policies".

As duas principais teorias a escola keynesiana são o modelo IS-LM de John Hicks e a curva de Phillips. O modelo IS-LM ("Interest Saving/Liquidity preference Money Supply") nada mais é que uma teoria de equilíbrio entre o lado real e monetário da economia. O lado real da economia é representado pela curva IS, onde a variável independente é a taxa de juros e a variável dependente é a produção (ou PIB). Assim, dado um nível de taxas de juros ("Interest"), os investimentos do setor privado são planejados. Esse investimento é financiado pela poupança do país ("Savings"), que se 
origina da economia das pessoas, do superávit no orçamento do governo (política fiscal) e do saldo da balança de pagamentos (poupança externa).

Já a curva LM representa o lado monetário da economia. Neste caso, temos como variável independente o produto (ou PIB) e a variável dependente é a taxa de juros. Cada ponto da curva LM corresponde a um ponto de equilíbrio entre a demanda de dinheiro, que é função crescente do produto e decrescente das taxas de juros, e a oferta de dinheiro, determinada pela política monetária.

A curva de Phillips surgiu a partir da observação empírica de uma relação entre a taxa de desemprego e os aumentos salariais (inflação). Os dados indicavam que uma maior inflação estava de certo modo associada a um menor desemprego. Assim, a implicação natural para a política econômica era que o governo poderia reduzir o desemprego caso aceitasse um nível de inflação maior. Entretanto, nos anos 70 o mundo passou por um período de alta inflação e alto desemprego, contrariando o que indicava a curva de Phillips. Assim, descobriu-se que a relação mais correta era entre o desemprego e a taxa de variação da inflação, o que levou à formulação da curva de Phillips aceleracionista. O modelo IS-LM e a teoria da curva de Phillips são apresentadas em detalhes no livro de Simonsen e Cysne (2007).

Neste trabalho, será apresentado um modelo que segue estruturas similares a de alguns estudos, como em Svensson (1997) e Orphanides e Wieland (2000), e aplica os conceitos da curva de Phillips e do modelo IS-LM. Esse tipo de estrutura, apesar de bem simples, permite o estudo dos conceitos mais importantes em política monetária. Além disso, apresenta como vantagem a facilidade de se ajustar a dinâmica do modelo aos dados e à estrutura recursiva, que permite a utilização das ferramentas de programação dinâmica para a determinação da política monetária ótima.

Considera-se então o modelo macroeconômico definido pelas equações 3.1 e 3.2 . A variável $i_{t}$ é a taxa de juros da economia (variável de controle), definido a cada período pela autoridade monetária. Já $\pi_{t}$ é a taxa de inflação e $h_{t}$ é o hiato do produto, já definidos na seção 3.1 . 
A primeira dessas equações é a versão aceleracionista da curva de Phillips, que considera a inflação do próximo período como uma função linear da inflação atual somado do hiato do produto e de um choque inflacionário $\epsilon_{\pi t}$. A segunda equação é a curva investimento-poupança (ou curva IS), modelando o hiato do produto no período seguinte como uma função linear do hiato atual somado a uma função linear dos juros reais da economia $\left(i_{t}-\pi_{t}\right)$ e a um choque de demanda $\epsilon_{h t}$.

$$
\begin{aligned}
& \pi_{t+1}=\beta \pi_{t}+\lambda y_{t}+\epsilon_{\pi t} \\
& h_{t+1}=\rho h_{t}-\sigma\left(i_{t}-\pi_{t}\right)+\epsilon_{h t}
\end{aligned}
$$

A ideia por trás da curva de Phillips é que um cenário de demanda aquecida (com um hiato do produto positivo) tende a pressionar o aumento da inflação, ou seja, $\lambda>0$. Porém, isso não impede que tenhamos uma situação com o hiato do produto positivo e inflação caindo já que a magnitude do choque $\epsilon_{\pi t}$ pode anular o efeito do hiato do produto na inflação.

Já a equação IS estabelece que quanto maiores os juros reais, ou seja, quanto maior a diferença entre o juro nominal $i_{t}$ e a inflação $\pi_{t}$, menor será o incentivo para consumir e, em consequência, menor será o hiato do produto. Para que o modelo seja consistente com a teoria, devemos ter $\sigma>0$.

É válido mencionar que os choques $\epsilon_{\pi t}$ e $\epsilon_{h t}$ têm origens distintas. O primeiro é um choque inflacionário e está geralmente ligado aos custos de produção, como preços das matérias primas. Um exemplo clássico foi o choque no preço do petróleo em 1973, motivado por fatores geopolíticos. Isso resultou no aumento da inflação em todos os países e em uma recessão nas economias desenvolvidas. Já o segundo tipo de choque $\left(\epsilon_{h t}\right)$ está relacionado à oferta e demanda por bens e serviços. Um exemplo são programas governamentais para incentivar o consumo, como o subsídio para compra de imóveis ou redução de impostos em bens de consumo. Assume-se que $\epsilon_{\pi t}$ e $\epsilon_{h t}$ são independentes, identicamente distribuídas (i.i.d). 
Pode-se reescrever as equações (3.1) e (3.2) na forma de espaço de estados.

$$
x_{t+1}=A x_{t}+B i_{t}+\eta_{t}
$$

Com

$$
x_{t}=\left[\begin{array}{l}
\pi_{t} \\
h_{t}
\end{array}\right], A=\left[\begin{array}{ll}
\beta & \lambda \\
\sigma & \rho
\end{array}\right], B=\left[\begin{array}{c}
0 \\
-\sigma
\end{array}\right], \eta_{t}=\left[\begin{array}{c}
\epsilon_{\pi t} \\
\epsilon_{h t}
\end{array}\right]
$$

O modelo apresentado tem como fundamento a teoria econômica clássica, adequandose aos dados empiricamente observados. Na forma como apresentado, é basicamente um modelo VAR(1) (vetor auto-regressivo) com uma variável de controle. Modelos de ordem maiores foram apresentados no artigo de Pindyck (1973).

Entretanto, esse modelo não funciona bem quando há alterações no ciclo econômico. Isso porque os agentes econômicos tomam suas decisões baseadas em expectativas para o futuro e não no que já passou. Essas expectativas para o futuro acabam por influenciar a situação presente pois, por exemplo, uma expectativa de alta de inflação faz com que as pessoas decidam consumir mais no presente como forma de proteger seu poder de compra, o que acaba levando a um aumento na demanda e pressionando ainda mais a inflação. Tal cenário não é explicado pela teoria econômica clássica. Assim, a teoria das expectativas racionais surge para tentar contornar esse problema, conforme será detalhado em seguida.

\subsection{Modelo Novo-Keynesiano}

Uma revolução na teoria econômica ocorreu com o surgimento da hipótese das expectativas racionais, derivada dos trabalhos de Muth (1961), Sargent e Wallace (1974), Lucas (1976), entre outros. Segundo essa hipótese, as previsões dos agentes econômicos para os valores futuros das variáveis economicamente relevantes não apresentam viés, o que significa que o erro de previsão é um ruído branco.

A crítica contida no artigo de Lucas (1976) sugere que, se um modelo tenta prever 
o resultado de uma política econômica, deve levar em consideração parâmetros estruturais que governam o comportamento individual, de modo que se pode prever o que os indivíduos farão, levando em consideração a mudança na política. Assim, os modelos até então empregados para determinar as políticas ótimas estavam errados, pois conforme as palavras do autor: "Given that the structure of an econometric model consists of optimal decision rules of economic agents, and that optimal decision rules vary systematically with changes in the structure of series relevant to the decision maker, it follows that any change in policy will systematically alter the structure of econometric models.".

Assim, a análise dos micro-fundamentos (comportamento dos agentes individuais) passa a ser obrigatória para a construção de um modelo macroeconômico consistente. Dessa forma, o modelo Novo-Keynesiano procura partir de micro-fundamentos para gerar um modelo agregado da economia. Nesse contexto, a economia é dividida em três setores: famílias, empresas e governo. As famílias estão constantemente maximizando sua capacidade de consumo, as empresas maximizam o lucro e o governo maximiza uma função de bem estar da sociedade. A dinâmica da economia deriva da iteração entre as decisões desses três agentes. Esse tipo de modelo é também chamado de DSGE (Dynamic Stochastic General Equilibrium).

Os economistas da linha Novo-Keynesiana argumentam que uma política monetária expansionista (baixa de juros) para aumentar o consumo e reduzir o desemprego não é recomendável no longo prazo, pois aumenta a inflação no futuro. Entretanto, eles recomendam a utilização de política monetária ativa para a correção dos choques que atingem a economia. Por exemplo, um choque inflacionário deve ter como resposta um aumento na taxa de juro. Assim, os estudos de otimização em modelos DSGE focam em estabelecer a resposta do governo aos choques na economia.

Seguindo a modelagem Novo-Keynesiana, há basicamente dois grupos de variáveis a serem consideradas. O primeiro deles são as variáveis autorregressivas (ou BackwardLooking), cuja dinâmica é dada pela soma de valores passados com variáveis aleatórias. 
O segundo grupo é o das variáveis antecipativas (ou Forward-Looking), nas quais o valor em cada período depende das expectativas para o futuro.

De modo geral, uma variável autorregressiva pode ser escrita como:

$$
z_{t+1}=\sum_{i=0}^{t} \phi_{i} z_{i}+\epsilon_{t}
$$

onde $\phi_{i}$ é um parâmetro do modelo.

Já uma variável antecipativa depende das expectativas para o futuro, ou seja, o valor da variável no instante $t$ depende da expectativa para o valor da variável no instante $t+1$. Assim, escreve-se:

$$
x_{t}=\phi_{x} E\left(x_{t+1} \mid t\right)+\epsilon_{t}
$$

Para simplificar a notação, escreve-se $x_{t+1 \mid t}=E\left(x_{t+1} \mid t\right)$ e $x_{t \mid t}=x_{t}=E\left(x_{t} \mid t\right)$.

O modelo novo-keynesiano considera a interação entre variáveis antecipativas e autorregressivas. Seja então $z_{t}$ um vetor $n_{z} \times 1$ de variáveis autorregressivas, $x_{t} \mathrm{um}$ vetor $n_{x} \times 1$ de variáveis antecipativas. De modo geral, podemos escrever um modelo da seguinte forma:

$$
H\left[\begin{array}{c}
z_{t+1} \\
x_{t+1 \mid t}
\end{array}\right]=D\left[\begin{array}{l}
z_{t} \\
x_{t}
\end{array}\right]
$$

Observando o modelo em detalhes, nota-se que $z_{t+1}$ depende de $z_{t}$ e $x_{t}$, ou seja, $z_{t}$ é a variável regressiva tradicional. Já a variável antecipativa $x_{t}$ não possui uma equação recursiva. Do modelo observa-se que $x_{t+1 \mid t}$ é função de $x_{t}$ e $z_{t}$. Isso nada mais é do que uma identidade algébrica, ou seja, conhecendo-se o $z_{t}$ e a expectativa condicional $x_{t+1 \mid t}$, calcula-se o valor de $x_{t}$.

Nesse trabalho será considerado um modelo Novo-Keynesiano simples, com a inflação e o hiato do produto como variáveis antecipativas. O modelo pode ser definido 
pelas equações:

$$
\begin{aligned}
\pi_{t} & =\beta E\left[\pi_{t+1} \mid t\right]+\lambda h_{t}+\epsilon_{\pi t} \\
E\left[h_{t+1} \mid t\right] & =h_{t}+\sigma\left(i_{t}-E\left[\pi_{t+1} \mid t\right]\right)+\epsilon_{h t}
\end{aligned}
$$

A equação (3.6) é a curva de Phillips antecipativa (forward-looking), que é obtida por meio da maximização da função utilidade das famílias. Já a equação (3.7) é a curva IS forward-looking, obtida pela da maximização dos lucros das empresas. O artigo de Clarida et al. (1999) apresenta mais detalhes sobre a formulação novo-keynesiana.

Há duas fontes de ruído (ou choque) no modelo, $\epsilon_{\pi t}$ e $\epsilon_{h t}$, que seguem um processo auto-regressivo $\mathrm{AR}(1)$ definido por:

$$
\begin{aligned}
& \epsilon_{\pi t+1}=\tau_{\pi} \epsilon_{\pi t}+\varsigma_{\pi t+1} \\
& \epsilon_{h t+1}=\tau_{h} \epsilon_{h t}+\varsigma_{h t+1}
\end{aligned}
$$

Onde $\varsigma_{\pi}$ e $\varsigma_{h}$ são ruídos branco independentes.

Pode-se reescrever as equações (3.6) a 3.9 como:

$$
\left[\begin{array}{cccc}
1 & 0 & 0 & 0 \\
0 & 1 & 0 & 0 \\
0 & 0 & \beta & 0 \\
0 & 0 & \sigma & 1
\end{array}\right]\left[\begin{array}{c}
\epsilon_{\pi t+1} \\
\epsilon_{h t+1} \\
E\left[\pi_{t+1} \mid t\right] \\
E\left[h_{t+1} \mid t\right]
\end{array}\right]=\left[\begin{array}{cccc}
\tau_{\pi} & 0 & 0 & 0 \\
0 & \tau_{h} & 0 & 0 \\
-1 & 0 & 1 & -\lambda \\
0 & 1 & 0 & 1
\end{array}\right]\left[\begin{array}{c}
\epsilon_{\pi t} \\
\epsilon_{h t} \\
\pi_{t} \\
h_{t}
\end{array}\right]+\left[\begin{array}{c}
0 \\
0 \\
0 \\
\sigma
\end{array}\right] i_{t}+\left[\begin{array}{c}
\varsigma_{\pi t+1} \\
\varsigma_{h t+1} \\
0 \\
0
\end{array}\right]
$$

Usando uma notação mais compacta, temos:

$$
H\left[\begin{array}{c}
z_{t+1} \\
E\left[x_{t+1} \mid t\right]
\end{array}\right]=A\left[\begin{array}{c}
z_{t} \\
x_{t}
\end{array}\right]+B i_{t}+C \xi_{t+1}
$$

onde $z_{t}$ é um vetor de variáveis predeterminadas, ou backward-looking (neste caso $\epsilon_{h t}$ e $\epsilon_{\pi t}$ ), e $x_{t}$ é um vetor de varáveis antecipativas, ou forward-looking (neste caso $\pi_{t+1}$ e 
$\left.h_{t+1}\right)$.

O modelo escrito na forma da equação (3.11) corresponde à formulação da teoria das expectativas racionais e possui uma série de peculiaridades que são bem estudadas no artigo de Blanchard (1983). 


\section{Capítulo 4}

\section{Estimação de parâmetros}

\subsection{Descrição do Problema}

No capítulo 3 foram apresentados os modelos (3.3) e 3.11) para representar a dinâmica da economia. Esses modelos são descritos pelos parâmetros $\beta, \sigma, \lambda$ e $\rho$ no caso do modelo (3.3) e pelos parâmetros $\beta, \sigma, \lambda, \tau_{\pi}$ e $\tau_{h}$ no caso do modelo (3.11. Assim, o objetivo neste capítulo é determinar esses parâmetros para permitir a realização de simulações numéricas com as leis de controle.

Para a determinar os parâmetros que melhor se ajustam aos dados é necessária a utilização de métodos estatísticos, conforme mostrado na seção 4.3 . Entretanto, antes de começar o processo de estimação deve-se obter as séries temporais para as variáveis do modelo. Isso leva a um outro problema: o hiato do produto, que é uma das variáveis do modelo, não é observável, ou seja, não se dispõe uma série temporal para essa variável.

Muitas metodologias já foram propostas para estimar o hiato do produto. O artigo Cusinato et al. (2010) resume os métodos de extração de tendências. Já o artigo Areosa (2008) mostra a estimação do hiato do produto pelo uso de funções de produção, relacionando o hiato do produto com a utilização da capacidade instalada e o desemprego. Exemplos de estimativas de parâmetros para os Estados Unidos, Reino Unido e Austrália são apresentados em Neiss e Nelson (2002). Assim, a seção 4.2 mostra métodos 
que permitem a estimação da variável não-observável a partir de dados observáveis.

\subsection{Hiato do Produto}

O hiato do produto é definido como a diferença entre o produto (PIB) e o produto potencial. Já o produto potencial é definido como a taxa de crescimento do produto com plena utilização dos fatores de produção e sem causar pressões inflacionárias. Portanto, pode-se considerar que o produto é a soma de um componente de tendência, o PIB potencial, e um componente cíclico, o hiato do produto. Escreve-se:

$$
p_{t}=p_{t}^{*}+h_{t}
$$

Onde $p_{t}$ é o logaritmo do produto, $p_{t}^{*}$ é o logaritmo do produto potencial e $h_{t}$ é o hiato do produto.

A literatura considera dois métodos para estimar o hiato do produto: o primeiro deles é o filtro de Hodrick e Prescott e o segundo é o método de Havey e Clark, os quais serão apresentados a seguir.

\subsubsection{Filtro de Hodrick e Prescott}

O filtro de Hodrick e Prescott, ou filtro HP, é um dos métodos mais frequentes na literatura para estimar o hiato do produto. Conforme mostrado em Hodrick e Prescott (1997), o produto potencial é determinado por meio da minimização da seguinte função custo:

$$
M=\sum_{t=1}^{T}\left(p_{t}-p_{t}^{*}\right)^{2}+\lambda \sum_{t=2}^{T-1}\left(\left(p_{t+1}^{*}-p_{t}^{*}\right)-\left(p_{t}^{*}-p_{t-1}^{*}\right)\right)^{2}
$$

onde $\lambda$ é um parâmetro de ajuste. Será utilizado o mesmo valor empregado por Hodrick e Prescott (1997), ou seja, $\lambda=1600$.

O primeiro termo da equação 4.2 penaliza os resíduos altos ("poor fit") e o segundo termo penaliza grandes variações no produto potencial. O parâmetro $\lambda$ faz a pondera- 
ção entre os dois termos. Como o valor do produto $p_{t}$ é dado, a equação 4.2 deve ser minimizada por meio da escolha da sequência de valores para o produto potencial $p_{t}^{*}$. Uma vez determinado o produto potencial, o hiato do produto fica determinado pela diferença entre o PIB e o produto potencial.

$$
h_{t}=p_{t}-p_{t}^{*}
$$

Uma solução fechada para o problema de otimização pode ser encontrada. Inicialmente deve-se reescrever o problema na forma matricial, conforme mostrado na equação 4.4.

$$
M=\left(P-P^{*}\right)\left(P-P^{*}\right)^{T}+\lambda P^{* T} K^{T} K P^{*}
$$

$\operatorname{Com} P=\left[\begin{array}{llll}p_{1} & p_{2} & \cdots & p_{n}\end{array}\right], P^{*}=\left[\begin{array}{llll}p_{1}^{*} & p_{2}^{*} & \cdots & p_{n}^{*}\end{array}\right]$

e $K=\left[\begin{array}{cccccccc}1 & -2 & 1 & 0 & \cdots & 0 & 0 & 0 \\ 0 & 1 & -2 & 1 & \cdots & 0 & 0 & 0 \\ \vdots & \vdots & \vdots & \vdots & \cdots & \vdots & \vdots & \vdots \\ 0 & 0 & 0 & 0 & \cdots & 1 & -2 & 1\end{array}\right]$

O problema de minimização pode ser resolvido com a utilização da condição de primeira ordem:

$$
\frac{\partial M}{\partial P^{*}}=0
$$

Assim, o cálculo da derivada parcial na equação (4.4), resolvido com o auxílio das propriedades do apêndice A, leva a:

$$
\frac{\partial M}{\partial P^{*}}=-2 P+2 P^{*}+2 \lambda K^{T} K P^{*}=0
$$

Ou seja, conclui-se que a solução do problema de otimização do filtro HP é dada pela equação 4.7.

$$
P^{*}=\left(I+\lambda K^{T} K\right)^{-1} P
$$

Com a utilização dos dados trimestrais do PIB brasileiro entre 1996 e 2010, obtém- 


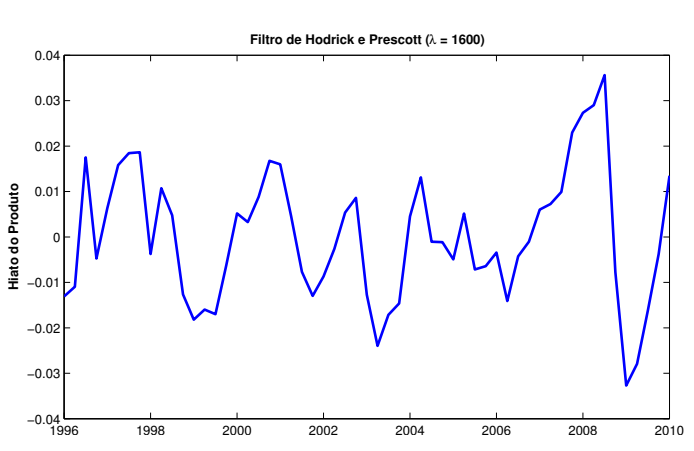

Figura 4.1: Hiato do Produto

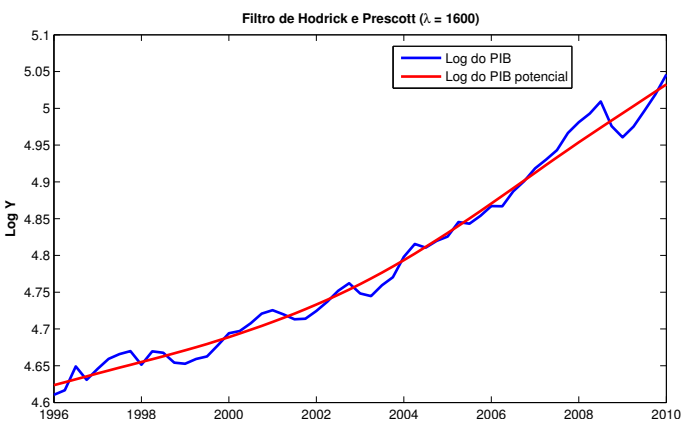

Figura 4.2: PIB Potencial

se o hiato do produto mostrado na figura 4.1. A comparação entre o PIB e o PIB potencial é mostrado na figura 4.2 .

Segundo o artigo de Hodrick e Prescott (1997), é necessário verificar se a série obtida para o hiato do produto possui raiz unitária, o que pode ser feito por meio do teste ADF ("Augmented Dickey-Fuller"). A presença de raiz unitária indica que a série temporal não é estacionária, impossibilitando a aplicação dos teoremas sobre séries temporais. Caso uma série temporal possua raiz unitária, o procedimento consiste em criar uma nova série a partir da primeira diferença dos elementos da série original.

O teste ADF tem como hipótese nula a existência de raiz unitária. A estatística ADF é calculada como o valor do coeficiente de auto-regressão da série dividido pelo desvio padrão do coeficiente estimado. Quanto maior o valor o valor absoluto da estatística ADF, maior a probabilidade de rejeitar a hipótese nula. Conforme mostrado na tabela 4.1, o hiato do produto não apresenta raiz unitária para o parâmetro escolhido $(\lambda=1600)$.

\subsubsection{Método de Havey e Clark}

Uma outra classe de métodos para estimar o hiato do produto utiliza modelos de componentes não observáveis, e um dos mais simples é o método de Harvey e Clark, apresentado em Harvey (1985), que decompõe o PIB em um termo de tendência e um termo cíclico de modo análogo ao filtro HP. Entretanto, esse modelo assume que o produto potencial segue um passeio aleatório com drift, onde esse drift é dado por 
Tabela 4.1: Teste da Raiz Unitária para a série do hiato do produto

\begin{tabular}{|ccccc|}
\hline & $\lambda=400$ & $\lambda=1600$ & $\lambda=6400$ & $\lambda \rightarrow \infty$ \\
\hline $\begin{array}{c}\text { Desvio Padrão } \\
\text { Autocorrelações }\end{array}$ & 1.36 & 1.44 & 1.58 & 2.80 \\
Lag 1 & 0.57 & 0.62 & 0.68 & 0.86 \\
Lag 2 & 0.12 & 0.20 & 0.33 & 0.72 \\
Lag 3 & -0.18 & -0.10 & 0.06 & 0.59 \\
Lag 4 & -0.39 & -0.32 & -0.13 & 0.51 \\
Lag 5 & -0.34 & -0.30 & -0.12 & 0.48 \\
Lag 6 & -0.25 & -0.25 & -0.11 & 0.43 \\
Lag 7 & -0.18 & -0.19 & -0.09 & 0.34 \\
Lag 8 & -0.16 & -0.18 & -0.11 & 0.24 \\
Lag 9 & -0.14 & -0.16 & -0.11 & 0.16 \\
Lag 10 & 0.01 & -0.02 & -0.02 & 0.11 \\
Estatística ADF & -3.73 & -3.52 & -3.08 & -1.44 \\
Rejeita Raiz Unitária & Sim & Sim & Sim & Não \\
\hline
\end{tabular}

um passeio aleatório normal. Além disso, assume que o hiato do produto segue um processo autorregressivo de segunda ordem $\operatorname{AR}(2)$. Escrevendo na forma de um sistema de equações:

$$
\begin{aligned}
& p_{t}=p_{t}^{*}+h_{t} \\
& p_{t}^{*}=\mu_{t-1}+p_{t-1}^{*}+\nu_{t} \\
& \mu_{t}=\mu_{t-1}+\omega_{t} \\
& h_{t}=\phi_{1} h_{t-1}+\phi_{2} h_{t-2}+\epsilon_{t}
\end{aligned}
$$

Os processos aleatórios $\nu_{t}, \omega_{t}$ e $\epsilon_{t}$ são não correlacionados com distribuição normal. Ao se reescrever o modelo na forma de espaço de estados, fica: 


$$
\begin{gathered}
{\left[\begin{array}{c}
p_{t}^{*} \\
h_{t} \\
h_{t-1} \\
\mu_{t}
\end{array}\right]=\left[\begin{array}{llll}
1 & 0 & 0 & 1 \\
0 & \phi_{1} & \phi_{2} & 0 \\
0 & 1 & 0 & 0 \\
0 & 0 & 0 & 1
\end{array}\right]\left[\begin{array}{c}
p_{t-1}^{*} \\
h_{t-1} \\
h_{t-2} \\
\mu_{t-1}
\end{array}\right]+\left[\begin{array}{c}
\nu_{t} \\
\epsilon_{t} \\
0 \\
\omega_{t}
\end{array}\right]} \\
p_{t}=\left[\begin{array}{llll}
1 & 1 & 0 & 0
\end{array}\right]\left[\begin{array}{c}
p_{t}^{*} \\
h_{t} \\
h_{t-1} \\
\mu_{t}
\end{array}\right]
\end{gathered}
$$

Os parâmetros desconhecidos são $\phi_{1}, \phi_{2}$ e as variâncias dos processos $\nu, \epsilon$ e $\omega$. Esses cinco parâmetros são determinados por máxima verossimilhança. As variáveis de estado são estimadas por um filtro de Kalman. Assim, é necessário implementar um processo iterativo onde a cada iteração um conjunto de parâmetros é fornecido, o filtro de Kalman fornece as estimativas dos estados e da saída, e a verossimilhança é determinada pelo erro entre a saída fornecida pelo filtro de Kalman e os valores reais.

O algoritmo apresentado em Kin e Nelson (1999) mostra a solução do problema. Uma forma alternativa para otimizar a log-verossimilhança é a aplicação do algoritmo genético para encontrar os parâmetros ótimos. Esses dois métodos foram aplicados no problema. O algoritmo de Kin e Nelson (1999) apresentou uma convergência muito mais rápida, entretanto o sucesso do algoritmo depende da escolha apropriada da condições iniciais. Já o algoritmo genético busca a solução ótima global e não depende tanto das condições iniciais. Esse último método apresentou um resultado levemente melhor, embora tenha demorado dez vezes mais para chegar na solução, conforme mostra a figura 4.3 .

A comparação entre os resultados obtidos pelo método de Harvey-Clark e pelo o filtro de Hodrick-Prescott é mostrada na figura 4.4. Observa-se que os resultados são bastante semelhantes, com exceção do período inicial da série. Nos primeiros dois anos, 


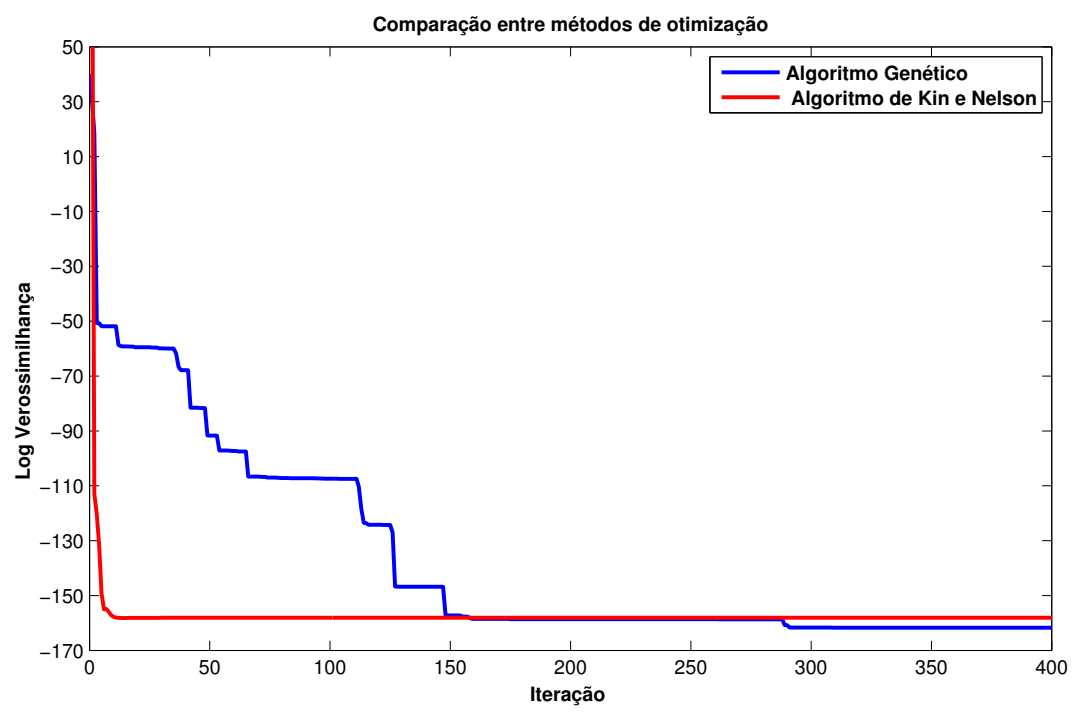

Figura 4.3: Comparação entre Algoritmos

a diferença é em torno de $2 \%$. Após esse período, a diferença se mantém bem pequena, alcançando no máximo 0,5\%.

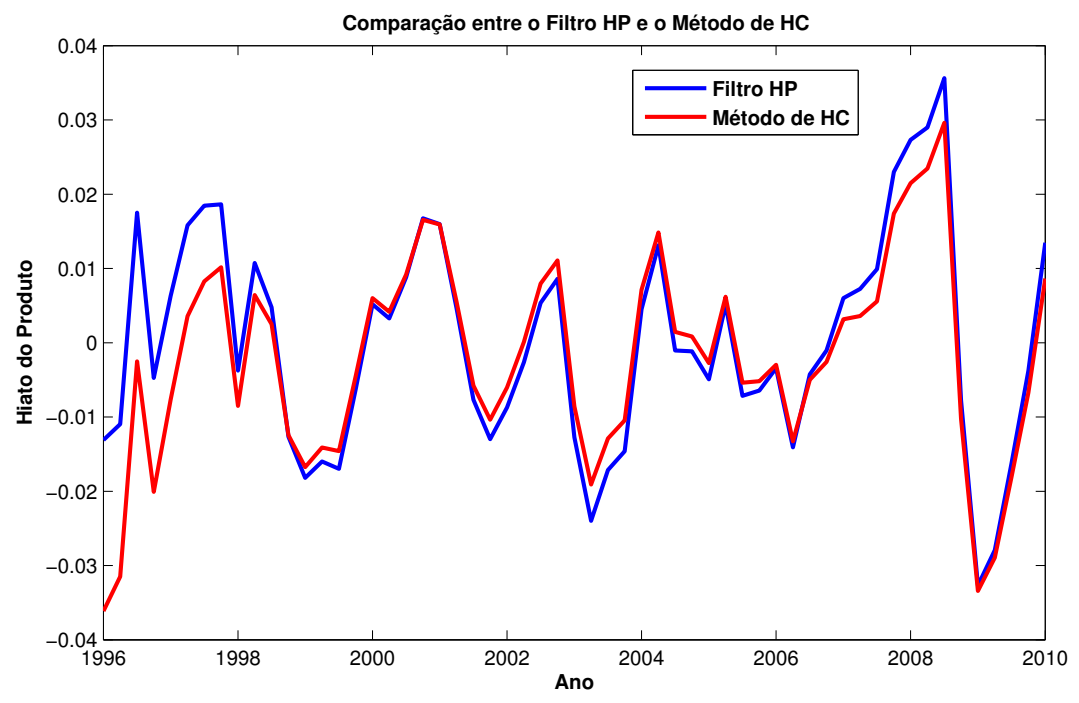

Figura 4.4: Comparação entre Métodos

\subsection{Estimação de Parâmetros}

Na seção anterior foi mostrado como obter a série temporal para o hiato do produto. Como o período de interesse para estimar os parâmetros será de 2001 a 2010, não há 
grandes diferenças entre os resultados do método HC ou do filtro HP. Por isso, serão utilizados os dados obtidos pelo filtro HP. A inflação é uma outra variável presente nos modelos e, nesse caso, será usado a série do IPCA (índice de preços ao consumidor amplo), pois é esse é o indicador que o Banco Central do Brasil utiliza no acompanhamento da meta de inflação.

O modelo novo-keynesiano também leva em consideração as expectativas para as variáveis. A expectativa da inflação pode ser obtida pelo relatório Focus, publicado semanalmente pelo Banco Central. Infelizmente, esse relatório começou a ser publicado em 2001, o que implica em uma série de dados relativamente curta. Nesse relatório, também é disponibilizada a expectativa para o PIB, a partir da qual se extraí a expectativa para o hiato do produto usando o filtro HP.

Uma vez que todas as séries temporais relevantes estão disponíveis, o próximo passo é a determinação dos parâmetros do modelo. A forma mais imediata de resolver o problema é utilizar o estimador de mínimos quadrados (Ordinary Least Squares $O L S)$, que determina os parâmetros que minimizam o erro médio quadrático entre o valor previsto pelo modelo e o valor medido. Entretanto, esse estimador só é ótimo se os erros tiverem uma distribuição normal, o que nem sempre ocorre nas séries de dados econômicas.

O estimador $O L S$ pode ser visto como um caso particular do método generalizado dos momentos (GMM), que parte da hipótese de que os resíduos são descorrelacionados das variáveis estimadas. O artigo de Gali et al. (2005) apresenta um exemplo de aplicação do GMM para a estimativa dos parâmetros de um modelo Novo-Keynesiano.

Por outro lado, o trabalho de Lindé (2001) considera que o estimador GMM produz estimativas enviesadas ("biased"), sendo necessários ajustes adicionais ao modelos, o que leva à um problema não linear (Non-Linear Least Squares - NLS). Em seguida, são apresentados os detalhes da estimação para cada modelo. 


\subsubsection{Estimação para o modelo keynesiano}

O modelo keynesiano é descrito pelas equações (3.1) e (3.2), apresentadas novamente abaixo.

$$
\begin{aligned}
& \pi_{t+1}=\beta \pi_{t}+\lambda h_{t}+\epsilon_{\pi t} \\
& h_{t+1}=\rho h_{t}-\sigma\left(i_{t}-\pi_{t}\right)+\epsilon_{h t}
\end{aligned}
$$

O primeiro questionamento na análise dos dados é a frequência de observação destes. Embora estejam disponíveis dados mensais para as variáveis, a interação entre taxas de juros, produto e inflação não é tão rápida, o que justifica a utilização de uma frequência trimestral de observação. O período considerado na análise é do primeiro trimestre de 2000 até o primeiro trimestre de 2010, totalizando 41 amostras.

Antes de aplicar o método de regressão, são necessários alguns ajustes aos dados. Inicialmente, observa-se que o sistema de equações possui um ponto de equilíbrio com $\pi_{t}=h_{t}=0$. Entretanto, a série de dados mostra que a inflação brasileira não esteve próxima de zero durante esses dez anos analisados. Como na verdade o modelo é uma linearização em torno do estado estacionário, assume-se que esse estado estacionário é o valor médio da inflação ao longo do período. Em seguida, calcula-se o desvio entre a inflação trimestral observada e seu valor médio e utiliza-se essa nova série para efetuar a regressão. Esse ajuste é repetido para o hiato do produto e para a taxa de juros.

Com os dados ajustados, a regressão é realizada usando o método dos mínimos quadrados ("ordinary least squares"). Cada equação é estimada separadamente. Para a equação (3.1) obtém-se $R^{2}=19,78 \%$ e $D W=1,82$. Já para a equação 3.2 as estatísticas da regressão são: $R^{2}=46,6 \%$ e $D W=1,34$. Os valores obtidos para os parâmetros são apresentados na tabela 4.2 .

A estatística DW (Durbin-Watson) é útil para detectar correlação serial nos resíduos da regressão. Quanto maior o valor, menor a probabilidade de correlação serial. Para o número de observações usadas, o valor mínimo da estatística DW deve ser 


\begin{tabular}{|c|c|c|}
\hline Parâmetro & Valor (desvio) & Estatística t \\
\hline$\beta$ & $0,4247(0,1455)$ & 2,9179 \\
$\lambda$ & $0,6067(0,5088)$ & 1,1923 \\
$\sigma$ & $0,0385(0,0387)$ & 0,9644 \\
$\rho$ & $0,7055(0,1226)$ & 5,7541 \\
\hline
\end{tabular}

Tabela 4.2: Parâmetros Estimados para o Modelo Keynesiano

1,20 (99\% de confiança). Assim as duas equações passam o teste. Já o $R^{2}$, também chamado de coeficiente de determinação, serve para avaliar a capacidade do modelo estimar corretamente os valores observados. As duas equações apresentam valores do $R^{2}$ aceitáveis, já que geralmente regressões em séries temporais econômicas apresentam baixo $R^{2}$.

Quanto aos parâmetros, além do valor estimado foi apresentado também o desvio padrão dessa estimação. A razão entre os dois é chamada de "estatística t", que está relacionada à probabilidade do parâmetro estimado ser nulo. Quanto mais alto o valor t, maior a probabilidade do parâmetro ser estatisticamente diferente de zero.

As figuras 4.6 e 4.5 mostram a comparação entre a série temporal observada e a série criada pelo modelo usando os parâmetros estimados.
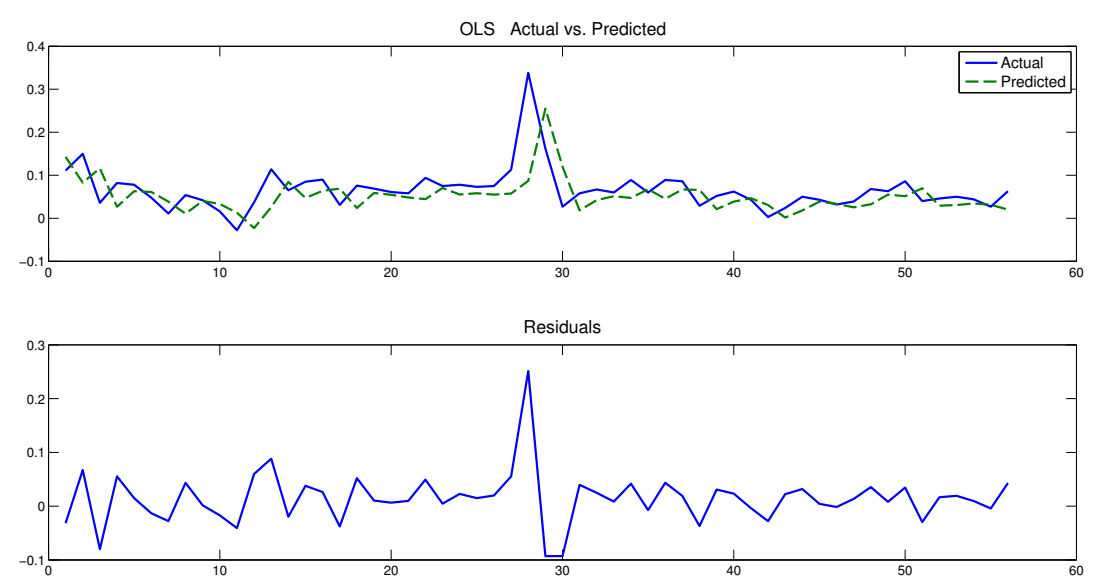

Figura 4.5: Resultados do Modelo para a Curva IS 

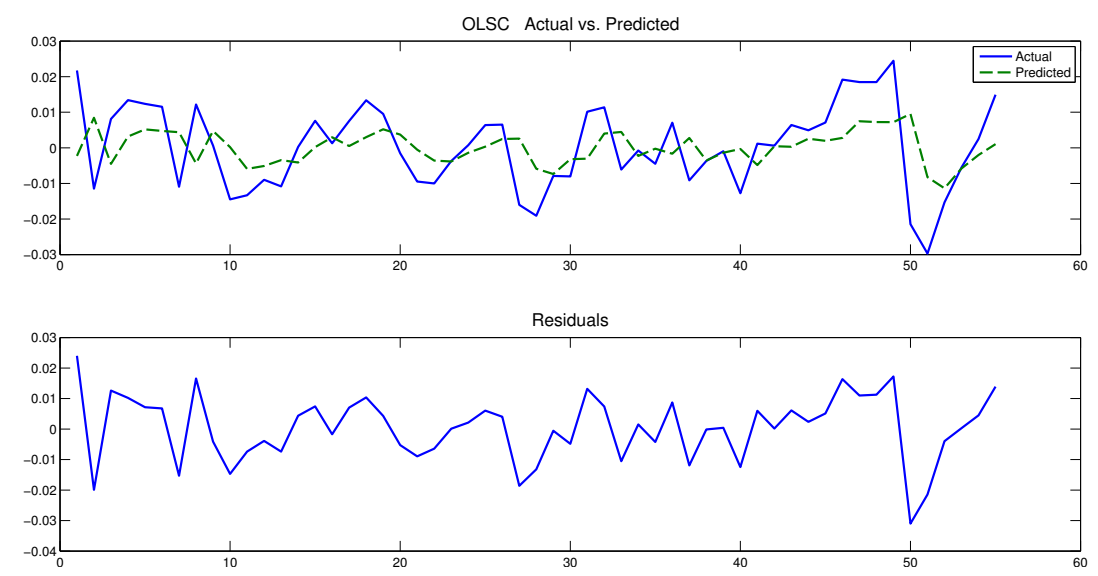

Figura 4.6: Resultados do Modelo para a Curva de Philips

\subsubsection{Estimação para o modelo novo-keynesiano}

Reescrevendo as equações do modelo novo-keynesiano, dadas pelas equações (3.6) e (3.7), tem-se:

$$
\begin{aligned}
\pi_{t} & =\beta E\left[\pi_{t+1} \mid t\right]+\lambda h_{t}+\epsilon_{\pi t} \\
E\left[h_{t+1} \mid t\right] & =h_{t}+\sigma\left(i_{t}-E\left[\pi_{t+1} \mid t\right]\right)+\epsilon_{h t}
\end{aligned}
$$

Para esse modelo, o processo de estimação é mais complexo devido à presença das expectativas. Conforme será mostrado no capítulo 5, os parâmetros devem satisfazer certas condições para que o modelo possua solução de equilíbrio. Em geral, a literatura considera três métodos de estimação: o método generalizado dos momentos (GMM), o método da máxima verossimilhança (ML) e o método de estimação Bayesiana.

O GMM consiste em estimar cada equação separadamente, por meio das condições de momento. Uma possível condição de momento é considerar o erro de estimação descorrelacionado do valor das variáveis. Além disso, deve-se considerar a hipótese de expectativas racionais, que considera a média do erro de estimação igual a zero. Por exemplo, para a equação (3.6), a hipótese de expectativas racionais fica:

$$
E\left(\pi_{t}-\beta \pi_{t+1}-\lambda h_{t}-\tau_{h} \epsilon_{h t-1} \mid t-1\right)=0
$$


Seja $Y_{t}$ um vetor com os dados observados e $\theta$ um vetor com os parâmetros. Então escreve-se a função vetorial $g\left(Y_{t}, \theta\right)$ como:

$$
g\left(Y_{t}, \theta\right)=\left[\pi_{t}-\beta \pi_{t+1}-\lambda h_{t}-\tau_{h} \epsilon_{h t-1}\right]
$$

Seja também $Z_{t}$ um vetor com os instrumentos observados $\left(Z_{t}=\pi_{t-1}, h_{t-1}\right)$. Escrevese a função vetorial $\phi_{t}$ como:

$$
\phi_{t}(\theta)=g\left(Y_{t}, \theta\right) Z_{t}
$$

O objetivo é encontrar o conjunto de parâmetros que minimiza a norma do vetor $\phi$, ou seja:

$$
\min _{\theta} S_{T}(\theta)=\left[T^{-1 / 2} \sum_{t=1}^{T} \phi_{t}(\theta)\right]^{T} W_{T}\left[T^{-1 / 2} \sum_{t=1}^{T} \phi_{t}(\theta)\right]
$$

$W$ é uma matriz de ponderação escolhida de modo a minimizar a variância dos estimadores, ou seja:

$$
W_{T}=\Omega^{-1}, \Omega=E\left[T^{-1 / 2} \sum_{t=1}^{T}\left(\phi_{t}(\theta)-E\left[\phi_{t}(\theta)\right]\right) T^{-1 / 2} \sum_{t=1}^{T}\left(\phi_{t}(\theta)-E\left[\phi_{t}(\theta)\right]\right)^{T}\right]
$$

Dessa forma, os valores estimados para os parâmetros são apresentados na tabela 4.3. Nota-se que a estatística-t é baixa para os parâmetros $\lambda, \sigma$ e $\tau_{h}$. Para os demais parâmetros, a estatística-t fornece valores altos.

\begin{tabular}{|c|c|c|}
\hline Parâmetro & Valor (desvio) & Estatística t \\
\hline$\beta$ & $0,8735(0,076)$ & 11,49 \\
$\lambda$ & $-0,2945(0,440)$ & 0,66 \\
$\sigma$ & $0,0086(0,0207)$ & 0,42 \\
$\tau_{\pi}$ & $-0,1664$ & 1,24 \\
$\tau_{h}$ & 0,0876 & 0,65 \\
\hline
\end{tabular}

Tabela 4.3: Parâmetros Estimados para o Modelo Novo-Keynesiano

As figuras 4.7 e 4.8 mostram os valores previstos e estimados pelo modelo novokeynesiano. 

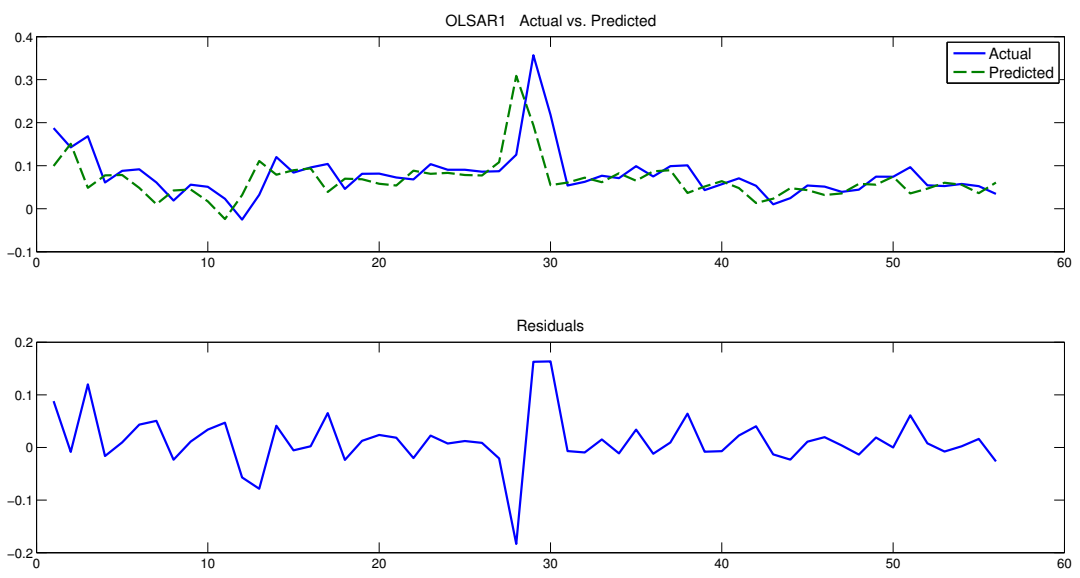

Figura 4.7: Resultados do Modelo para a Curva IS Antecipativa
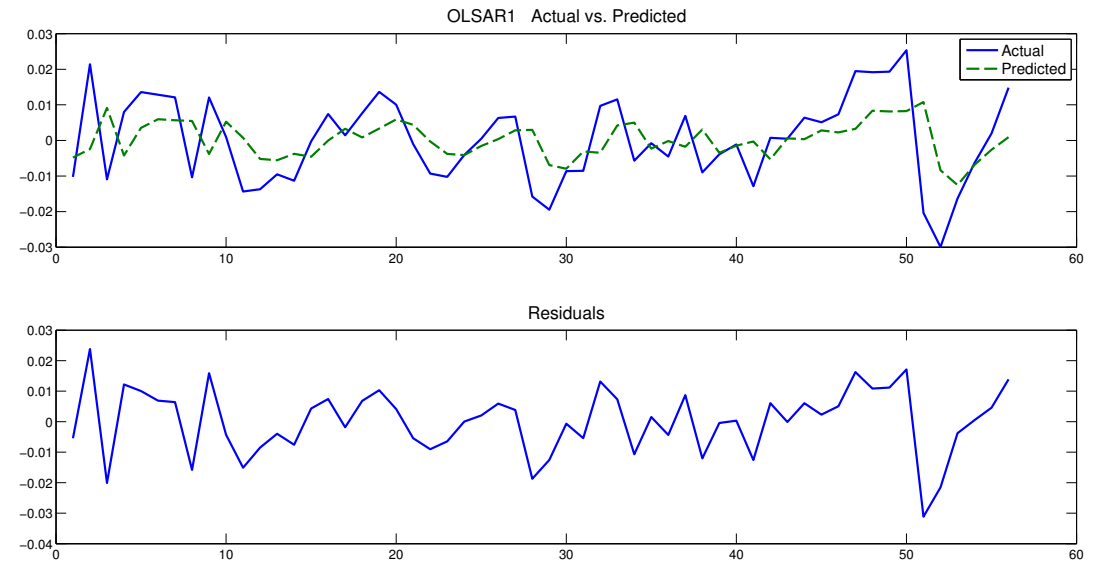

Figura 4.8: Resultados do Modelo para a Curva de Philips Antecipativa 


\section{Capítulo 5}

\section{Problema de Controle Ótimo}

\subsection{Considerações Gerais}

O objetivo de uma política de controle ótimo é fazer com que o vetor de estados, $x_{i}$, siga o mais próximo possível uma certa trajetória $\bar{x}_{i}$ por meio da aplicação do controle $u_{t}$. Entretanto, essa variável de controle não pode ser manipulada livremente, existindo um custo para a aplicação do controle.

Assim, neste capítulo é determinado o controle ótimo para os modelos definidos pelas equações 3.3 e 3.11. Enquanto que o primeiro modelo pode ser resolvido usando as ferramentas de programação dinâmica estocástica, o segundo modelo não está na forma recursiva para a aplicação desse método. Entretanto, conforme será mostrado, o modelo 3.11 pode ser reescrito numa forma recursiva após a aplicação de uma série de transformações.

Independentemente do modelo adotado, a função custo da economia é dada por:

$$
J=E\left[\sum_{t=0}^{\infty} \delta^{t} L_{t}\right]
$$

onde $\delta$ é um fator de desconto e:

$$
L_{t}=\left(\pi_{t}-\pi^{*}\right)^{2}+\lambda_{h}\left(h_{t}-h^{*}\right)^{2}+\lambda_{i}\left(i_{t}-i^{*}\right)^{2}
$$


Ao o longo deste capítulo, o problema de controle ótimo, que consiste em minimizar a função objetivo (5.1) sujeito à equação dinâmica, será resolvido para os dois modelos dinâmicos anteriormente apresentados.

\subsection{Controle Ótimo no modelo Keynesiano}

Conforme mostrado no capítulo 3, o modelo keynesiano para a economia pode ser resumido segundo a equação 3.3 , ou seja

$$
x_{t+1}=A x_{t}+B i_{t}+\eta_{t}
$$

onde assume-se que a variável $\eta$ possui uma distribuição normal.

O problema é encontrar a sequência de taxas $i_{t}$ que minimizam a função custo $J$ :

$$
\min _{i_{t}} J=E\left[\sum_{t=0}^{\infty} \delta^{t} L_{t}\right]
$$

sujeito à equação dinâmica (3.3).

\subsubsection{Formulação LQR}

Neste caso, a função custo é quadrática e o sistema é linear (controle LQ). Entretanto, o problema é um pouco diferente do regulador, pois o objetivo é deixar o sistema em um ponto de equilíbrio diferente de zero $\left(\pi^{*}, y^{*}\right.$ e $\left.i^{*}\right)$. Para que a solução seja possível, é necessário que esses valores também satisfaçam a equação dinâmica. Seguindo um procedimento análogo a Kwakernaak e Sivan (1972), escreve-se:

$$
x^{*}=A x^{*}+B i^{*} \Leftrightarrow x^{*}=(I-A)^{-1} B i^{*}
$$


Em seguida, aplica-se a mudança de variáveis:

$$
\begin{aligned}
& x_{t}^{\prime}=x_{t}-x^{*} \\
& i_{t}^{\prime}=i_{t}-i^{*}
\end{aligned}
$$

E reescreve-se o problema como um LQR:

$$
\begin{gathered}
\min _{i_{t}^{\prime}} \sum_{t=0}^{\infty} \delta^{t}\left(x_{t}^{\prime}\right)^{T} Q x_{t}^{\prime}+\delta^{t}\left(i_{t}^{\prime}\right)^{T} R i_{t}^{\prime} \\
\text { com }: x_{t+1}^{\prime}=A x_{t}^{\prime}+B i_{t}^{\prime}+\eta_{t}
\end{gathered}
$$

onde $Q$ e $R$ são

$$
Q=\left[\begin{array}{cc}
1 & 0 \\
0 & \lambda_{h}
\end{array}\right], R=\lambda_{i}
$$

Nesse caso, o controle ótimo é dado por:

$$
i_{t}^{\prime}=-\left(R+\delta B^{T} P B\right)^{-1} \delta B^{T} P A x_{t}^{\prime}
$$

Onde a matriz $P$ é obtida pela equação algébrica de Riccati:

$$
P=Q+\delta A^{T} P A-\delta A^{T} P B\left(R+\delta B^{T} P B\right)^{-1} \delta B^{T} P A
$$

O exemplo mostrado na figura 5.2.1 é o resultado de uma simulação numérica. As variáveis apresentadas são as definidas em (5.5). Assim, para retornar às variáveis iniciais, basta somar os valores de referência $\left(x^{*}\right.$ e $\left.i^{*}\right)$. Nota-se que o valor das metas de inflação não tem nenhuma influência na formulação do LQR.

\subsubsection{Formulação LQG}

Conforme mencionado anteriormente, o hiato do produto é uma variável não-observável. Além disso, as medições da inflação estão sujeitas a erros de medida. Dessa forma, pode-se considerar a formulação do controlador Linear Quadrático Gaussiano (LQG) 


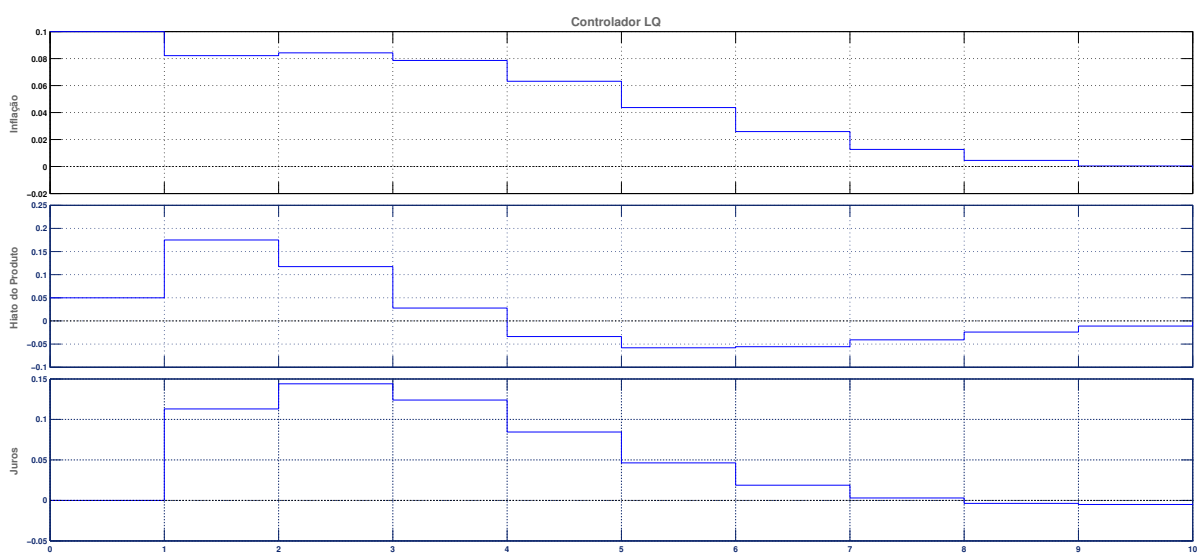

Figura 5.1: Exemplo de um controlador LQ

para a determinação da política de controle ótimo.

Assim, seja novamente o modelo definido pela equação (3.3). Será adicionado uma equação para as variáveis observadas, que é justamente a inflação somada de um erro de medida, conforme mostrado na equação $(5.9)$ abaixo.

$$
\begin{aligned}
x_{t+1} & =A x_{t}+B i_{t}+\eta_{t} \\
y_{t} & =H x_{t}+\omega_{t}
\end{aligned}
$$

com $H=\left[\begin{array}{ll}1 & 0\end{array}\right]^{T}$. Assume-se que $\omega_{t}$ e $\eta_{t}$ são ruído branco independentes, com matriz de covariância $W$ e $N$ respectivamente.

Segundo o Princípio da Separação, a solução de um problema desse tipo passa pela decomposição em dois novos problemas, conforme mostrado em Kwakernaak e Sivan (1972):

- Estimador linear quadrático (LQE): usado para estimar as variáveis de estado dado os valores medidos;

- Regulador linear quadrático (LQR): usado para determinar o controle ótimo, dado as estimativas do estado. 
O controlador LQG pode ser escrito como:

$$
\begin{aligned}
\hat{x}_{t+1} & =A \hat{x}_{t}+B i_{t}+L V_{t} \\
i_{t} & =-M \hat{x}_{t} \\
V_{t} & =y_{t}-H \hat{x}_{t}
\end{aligned}
$$

A matriz $L$ é o ganho do filtro de Kalman, e é dada por:

$$
L=\left(A P H^{T}\right)\left(H P H^{T}+W\right)^{-1}
$$

onde $P$ é determinada pela equação algébrica de Riccati:

$$
P=A P A^{T}+N-\left(A P H^{T}\right)\left(H P H^{T}+W\right)^{-1}\left(A P H^{T}\right)^{T}
$$

A solução dessa equação de Riccati, juntamente com a determinação do ganho de Kalman, resolvem o problema de estimação (LQE). O próximo passo é resolver o problema do LQR através da equação algébrica de Riccati. Assim, a matriz de ganho da realimentação é dada por:

$$
M=\left(B^{T} S B+R\right)^{-1} B^{T} S A
$$

onde $S$ é dado pela equação de Riccati:

$$
S=\delta A^{T} S A+Q-\left(\delta A^{T} S B\right)\left(\delta B^{T} S B+R\right)^{-1}\left(\delta A^{T} S B\right)^{T}
$$

O resultado de uma simulação para o controlador LQG é mostrado na figura 5.2 . Nessa simulação é considerado um sinal senoidal para a inflação e é mostrada a taxa de juros segundo o controlador LQG.

Por fim, é possível comparar a resposta à condições iniciais para os controladores LQG e LQR, conforme mostrado na figura 5.3. Na simulação, o controlador LQG 


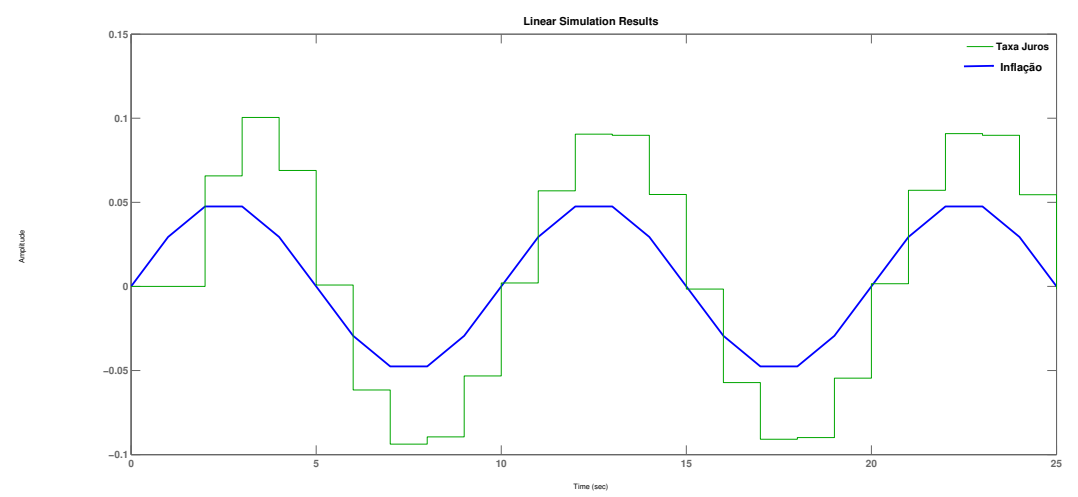

Figura 5.2: Controlador LQG

superestima o valor inicial do hiato do produto, o que explica as taxas de juros serem mais altas no caso LQG.

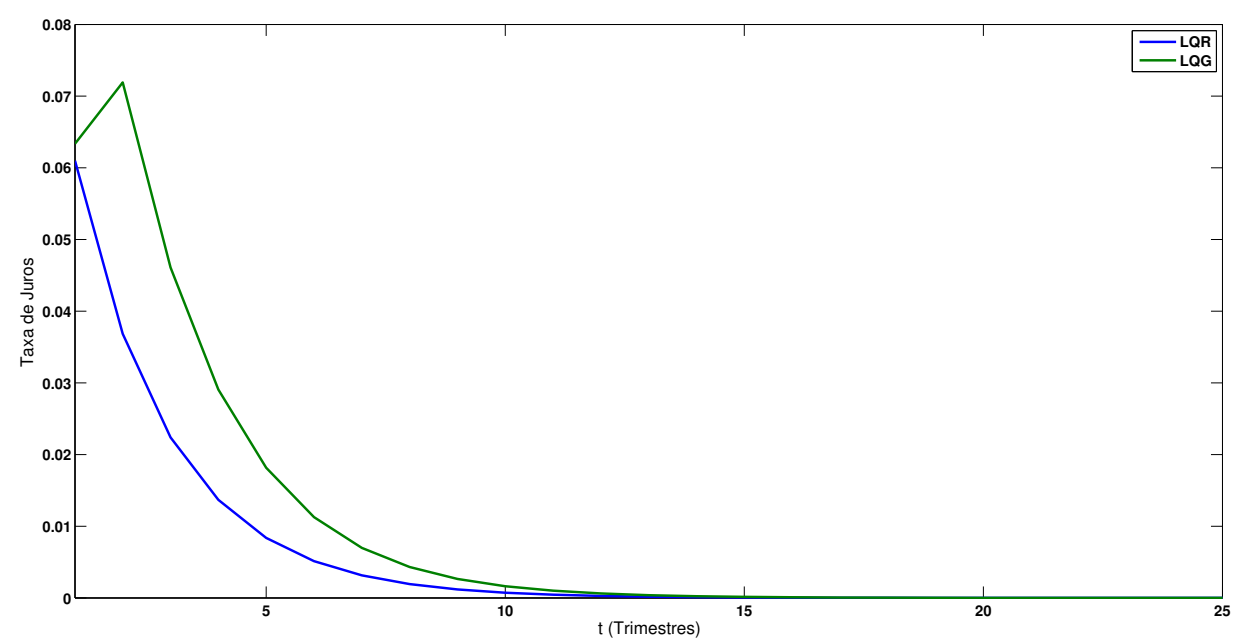

Figura 5.3: Controle Ótimo para os controladores LQG e LQR

\subsection{Controle Ótimo no Modelo Novo Keynesiano}

O modelo Novo Keynesiano é definido pela equação (3.11), conforme representado novamente abaixo.

$$
H\left[\begin{array}{c}
z_{t+1} \\
E\left[x_{t+1} \mid t\right]
\end{array}\right]=A\left[\begin{array}{c}
z_{t} \\
x_{t}
\end{array}\right]+B i_{t}+C \xi_{t+1}
$$


Conforme já apresentado, z é uma variável autorregressiva (também chamada de predeterminada) e possui condições iniciais, enquanto $x$ é uma variável antecipativa, sem condições iniciais. Assim, a dinâmica do modelo, pela forma como é apresentado, não é recursiva. É necessário, portanto, aplicar uma série de transformações para obter um modelo na forma usual. Entretanto, antes de apresentar as técnicas de controle será mostrado como resolver um modelo desse tipo, pois a ausência de condições iniciais torna o sistema bem peculiar.

\subsubsection{Métodos de Solução para Modelos com Expectativas Racionais}

A diferença entre o modelo dinâmico tradicional (3.3) e o modelo novo-keynesiano (3.11) é que o primeiro possui condições iniciais para todas as variáveis endógenas. Dado essas condições iniciais, o controle aplicado e os choques, é possível determinar a trajetória das variáveis de estado.

Já no modelo novo-keynesiano só existem condições iniciais para as variáveis predeterminadas. As variáveis antecipativas, como a inflação e o hiato do produto, não possuem condições iniciais. Assim o sistema fica indeterminado, e isso torna necessário a imposição de condições adicionais, chamadas de condições de transversalidade, para que o sistema possa ser resolvido.

Dessa forma, resolver um modelo com expectativas racionais consiste em encontrar as trajetórias para as variáveis de estado que satisfaçam o modelo dinâmico, as condições iniciais das variáveis predeterminadas e as condições de transversalidade das variáveis antecipativas, conforme mostrado em Blanchard (1983).

Porém, antes de apresentar o método para determinar a trajetória das variáveis de estado do modelo, cabe uma breve explicação sobre a origem do problema. Para isso, 
considera-se o modelo bem simples apresentado pela equação 5.12 abaixo:

$$
\left[\begin{array}{c}
x_{t+1} \\
z_{t+1}
\end{array}\right]=\left[\begin{array}{cc}
A_{11} & A_{21} \\
0 & A_{22}
\end{array}\right]\left[\begin{array}{c}
x_{t} \\
z_{t}
\end{array}\right]+\left[\begin{array}{c}
B_{1} \\
0
\end{array}\right] i_{t}+\left[\begin{array}{c}
0 \\
\nu_{t}
\end{array}\right]
$$

Esse modelo nada mais é que um modelo recursivo padrão. Agora formula-se um problema de otimização dada a função custo (5.13) abaixo:

$$
J=\frac{1}{2} E\left[\sum_{i=0}^{\infty} \delta^{i}\left(\left[\begin{array}{c}
x_{t+i} \\
z_{t+i}
\end{array}\right]^{T}\left[\begin{array}{ll}
Q_{11} & Q_{12} \\
Q_{12}^{T} & Q_{22}
\end{array}\right]\left[\begin{array}{c}
x_{t+i} \\
z_{t+i}
\end{array}\right]+i_{t+i}^{T} R i_{t+i}\right) \mid \Omega_{t}\right]
$$

com $\delta<1, R$ simétrica positiva definida, $Q$ simétrica positiva semidefinida e $\nu_{t}$ é ruido branco, $E\left(\nu_{t+1} \mid \Omega_{t}\right)=0$.

Um problema desse tipo distingue duas variáveis de estado. Enquanto $z$ só depende de seus valores passados e de um ruído aditivo, $x$ depende tanto de seus valores passados quanto de $z$ e do controle $i$. Um problema desse tipo poderia ser facilmente resolvido aplicando os métodos discutidos na seção 5.2. Entretanto, é mais interessante resolver usando o método dos multiplicadores de Lagrange. Assim, seja $\rho$ um vetor de multiplicadores de Lagrange (coestados) associado ao vetor x. Então escreve-se:

$$
\mathcal{L}=J+\rho_{t}\left(x_{t+1}-A_{11} x_{t}-A_{12} z_{t}-B_{1} i_{t}\right)
$$

Derivando as condições de primeira ordem, usando a restrição dada pela equação associada a $z_{t+1}$ e rearranjando, obtém-se:

$$
\begin{gathered}
{\left[\begin{array}{c}
x_{t+1} \\
E\left[\rho_{t+1} \mid t\right]
\end{array}\right]=\left[\begin{array}{cc}
A_{11} & B_{1} R^{-1} B_{1}^{T} \\
A_{11}^{T} Q_{11} A_{11} & A_{11}^{-T}\left(\delta^{-1} I+Q_{11} B_{1} R^{-1} B_{1}^{T}\right.
\end{array}\right]\left[\begin{array}{c}
x_{t} \\
\rho_{t}
\end{array}\right]+} \\
+ \\
{\left[\begin{array}{c}
A_{12} \\
A_{11}^{-T}\left(Q_{11} A_{12}+Q_{12} A_{22}\right)
\end{array}\right] z_{t}}
\end{gathered}
$$

Observa-se que a solução do problema de otimização é idêntico ao modelo (3.11, 
onde a variável antecipativa nada mais é que um multiplicador de Lagrange de um problema de otimização. Se o problema fosse a tempo finito, o multiplicador teria uma condição terminal. Entretanto como esse caso é um problema a tempo infinito, o multiplicador não possui nenhuma restrição e uma condição de transversalidade é adicionada para permitir a solução.

O método de Blanchard e Kahn (1980) foi inicialmente pensado para encontrar a solução de um sistema com expectativas racionais sem a variável de controle. Entretanto a variável de controle geralmente pode ser representada por uma equação recursiva permitindo que o sistema possa ser reescrito com o controle entre as variáveis de estado. De qualquer forma, sejam $z_{t}$ e $x_{t}$ como definido anteriormente. Para simplificar a notação, usa-se $E\left(x_{t+1} \mid t\right) \equiv x_{t+1 \mid t}$.

O primeiro passo é reescrever a equação (3.11) sem a variável de controle:

$$
H\left[\begin{array}{c}
z_{t+1} \\
x_{t+1 \mid t}
\end{array}\right]=A\left[\begin{array}{c}
z_{t} \\
x_{t}
\end{array}\right]+\left[\begin{array}{l}
C \\
0
\end{array}\right] \xi_{t+1}
$$

Aplica-se então um procedimento idêntico aos trabalhos de Soderlind (1999) e Sims (2002), que inicia-se pela decomposição generalizada de Schur às matrizes $A$ e $H$, o que permite encontrar as matrizes $Q, S$ e $T$, tal que:

$$
A=Q^{\prime} T Z^{\prime}
$$

$$
H=Q^{\prime} S Z^{\prime}
$$

As matrizes $Q$ e $Z$ são unitárias $\left(Q^{\prime} Q=Z^{\prime} Z=I\right)$ enquanto $T$ e $S$ são triangulares (superior). Os elementos das matrizes $T$ e $S$ definem os autovalores generalizados da decomposição: $\lambda_{j}=t_{j j} / s_{j j}$.

A propriedade do ponto de sela, conforme definido por Blanchard e Kahn (1980), afirma que o número de autovalores generalizados $\left(\lambda_{j}\right)$ com módulo maior que 1 (au- 
tovalores instáveis) são iguais ao número de variáveis antecipativas $z_{t}$. Define-se novas variáveis $\hat{y}_{1}$ e $\hat{y}_{2}$ como:

$$
\left[\begin{array}{c}
\hat{y}_{1 t} \\
\hat{y}_{2 t}
\end{array}\right] \equiv Z^{\prime}\left[\begin{array}{l}
z_{t} \\
x_{t}
\end{array}\right]
$$

Com a definição inicial (5.16), aplica-se o valor esperado condicional à informação disponível no instante $t$ e multiplica-se por $Q$ nos dois lados da igualdade. Como $E\left(\xi_{t+1} \mid t\right)=0$, a equação se resume a:

$$
Q H\left[\begin{array}{c}
E\left(z_{t+1} \mid t\right) \\
E\left(x_{t+1} \mid t\right)
\end{array}\right]=Q A\left[\begin{array}{c}
z_{t} \\
x_{t}
\end{array}\right]
$$

Conforme as definições (5.17), 5.18), 5.19) e o fato de $Q$ e $Z$ serem matrizes unitárias, obtém-se:

$$
\left[\begin{array}{cc}
S_{11} & S_{12} \\
0 & S_{22}
\end{array}\right]\left[\begin{array}{c}
E\left(\hat{y}_{1, t+1} \mid t\right) \\
E\left(\hat{y}_{2, t+1} \mid t\right)
\end{array}\right]=\left[\begin{array}{cc}
T_{11} & T_{12} \\
0 & T_{22}
\end{array}\right]\left[\begin{array}{l}
\hat{y}_{1 t} \\
\hat{y}_{2 t}
\end{array}\right]
$$

Isola-se o bloco inferior da equação (5.21), o que leva a:

$$
S_{22} E\left(\hat{y}_{2, t+1 \mid t}\right)=T_{22} \hat{y}_{2 t}
$$

Por hipótese, o módulo dos autovalores generalizados desse bloco inferior é maior que 1. Assim a solução para $\hat{y}_{2 t}$ é instável. Dessa forma, é preciso incluir uma condição de transversalidade para garantir que uma solução estável, que só pode ser alcançada com $\hat{y}_{2 t}$ sempre igual a zero:

$$
\hat{y}_{2 t}=T_{22}^{-1} S_{22} E\left(\hat{y}_{2, t+1} \mid t\right)=0
$$

De volta à equação $(5.19)$, multiplica-se por $Z$, usa-se o fato que $Z Z^{\prime}=I$ e aplica-se 
a condição de transversalidade (5.22), o que resulta em:

$$
Z\left[\begin{array}{c}
\hat{y}_{1 t} \\
0
\end{array}\right] \equiv\left[\begin{array}{c}
z_{t} \\
x_{t}
\end{array}\right]
$$

Decompondo a matriz $Z$, a equação (5.23) pode ser resolvida para $x_{t}$ e $z_{t}$ :

$$
\begin{aligned}
& z_{t}=Z_{11} \hat{y}_{1 t} \\
& x_{t}=Z_{21} \hat{y}_{1 t}
\end{aligned}
$$

Sob as hipóteses do teorema de Blanchard e Kahn, $Z_{11}$ é uma matriz quadrada. Além disso, assume-se que $Z_{11}$ é inversível. Dessa forma, a solução equação para as variáveis antecipativas é:

$$
x_{t}=Z_{21} Z_{11}^{-1} z_{t}
$$

Resta encontrar a solução para as variáveis predeterminadas. Aplicando a condição de transversalidade (5.22) à equação (5.21), o bloco superior dessa equação pode ser escrito como:

$$
S_{11} E\left(\hat{y}_{1, t+1} \mid t\right)=T_{11} \hat{y}_{1 t} \quad \Leftrightarrow \quad E\left(\hat{y}_{1, t+1} \mid t\right)=S_{11}^{-1} T_{11} \hat{y}_{1 t}
$$

Em seguida aplica-se o valor esperado à equação (5.24), o que leva a:

$$
\begin{gathered}
E\left(z_{t+1} \mid t\right)=Z_{11} E\left(\hat{y}_{1, t+1} \mid t\right) \\
E\left(z_{t+1} \mid t\right)=Z_{11} S_{11}^{-1} T_{11} \hat{y}_{1 t} \\
E\left(z_{t+1} \mid t\right)=Z_{11} S_{11}^{-1} T_{11} Z_{11}^{-1} z_{t}
\end{gathered}
$$


Definindo $M=Z_{11} S_{11}^{-1} T_{11} Z_{11}^{-1}$, a solução para as variáveis predeterminadas é:

$$
z_{t+1}=M z_{t}+C \epsilon_{t+1}
$$

\subsubsection{Política Ótima Simples}

A autoridade monetária pode se comprometer em implementar uma política do tipo $i_{t}=-\left(\chi \pi_{t}+\phi y_{t}\right)$. Define-se $F=\left[\begin{array}{llll}0 & 0 & \chi & \phi\end{array}\right]$ e substituí-se na equação 3.11 , o que resulta em:

$$
H\left[\begin{array}{c}
z_{t+1} \\
x_{t+1 \mid t}
\end{array}\right]=(A-B F)\left[\begin{array}{c}
z_{t} \\
x_{t}
\end{array}\right]+\left[\begin{array}{c}
C \\
0
\end{array}\right] \xi_{t+1}
$$

O modelo pode ser resolvido conforme a metodologia da seção 5.3.1, desde que se conheça os parâmetros $\chi$ e $\phi$. Esses parâmetros são escolhidos de modo a minimizar a função custo:

$$
\min _{i_{t}} E\left[\sum_{t=0}^{T}\left(\pi_{t}-\pi^{*}\right)^{2}+\lambda_{y}\left(y_{t}-y^{*}\right)^{2}+\lambda_{i}\left(i_{t}-i^{*}\right)^{2}\right]
$$

Como são apenas dois parâmetros a determinar, pode-se utilizar o algoritmo genético para obter-se a solução numérica do problema. O procedimento consiste em escolher parâmetros aleatórios, resolver o sistema e calcular a função custo. Entretanto, dependendo dos parâmetros escolhidos, as condições do teorema de Blanchard-Kahn podem não ser satisfeitas, o que faz com que o sistema não tenha solução. Esses conjuntos de parâmetros são excluídos, e o processo continua até se encontrar o par que minimiza a função custo ao mesmo tempo que satisfaz as restrições.

Entretanto, a suposição que a política de controle é proporcional às variáveis de estado é muito restritiva e pode levar a uma solução sub-ótima. Para contornar esse problema existem alguns métodos que permitem encontrar a solução ótima, como por exemplo o método do lagrangeano e o método do ponto de sela recursivo. 


\subsubsection{Método do Lagrangeano}

O método do lagrangeano explora a transformação da variável de controle em uma variável de estado por meio da inclusão de equações adicionais derivadas dos multiplicadores de lagrange e das condições de primeira ordem para a otimização. Assim, o sistema fica escrito de uma forma que permite a utilização do método de Blanchard e Kahn (1980) para resolver o sistema e encontrar o controle ótimo e as trajetórias das variáveis de estado.

Assim, seja $y_{t}=\left[\begin{array}{c}z_{t} \\ x_{t}\end{array}\right]$. Aqui $x$ continua como variável antecipativa. Para simplificar a notação considera-se $x_{t+1}=x_{t+1 \mid t}$. A função custo no instante $t$ pode ser escrita como:

$$
L_{t}=y_{t}^{\prime} Q y_{t}+i_{t}^{\prime} R i_{t}
$$

O custo total esperado $(J)$ é calculado usando um fator de desconto $\delta$ :

$$
J=E\left[\sum_{t=0}^{\infty} \delta^{t} L_{t}\right]
$$

Conforme a definição de $y_{t}$, o modelo apresentado pela equação 3.11 pode ser escrito:

$$
y_{t+1}=A y_{t}+B i_{t}+\epsilon_{t+1}
$$

Como o sistema é linear quadrático, o Princípio da Equivalência à Certeza pode ser aplicado, permitindo a simplificação do problema por meio da utilização de um modelo não-estocástico. Além disso, com a utilização da definição do vetor $y_{t}$ e o particionamento da matriz $A$, reescreve-se a equação 3.11 como:

$$
\left[\begin{array}{l}
z_{t+1} \\
x_{t+1}
\end{array}\right]=\left[\begin{array}{ll}
A_{11} & A_{12} \\
A_{21} & A_{22}
\end{array}\right]\left[\begin{array}{l}
z_{t} \\
x_{t}
\end{array}\right]+B u_{t}
$$

As condições iniciais para as variáveis autorregressivas $z_{t}$ são das pelo vetor $z_{0}$. Entretanto, não há condições iniciais para para as variáveis antecipativas, o que torna 
necessário a inclusão de condições de transversalidade para que uma solução possa existir, conforme mostrado em Blanchard (1983).

O problema é minimizar a equação (5.31), sujeito à dinâmica (5.32) e à condição inicial $x_{0}$, por meio da escolha da sequência de controles $\left\{i_{t}\right\}_{t=0}^{\infty}$.

O primeiro passo para a determinação da política de controle ótimo consiste em escrever o Lagrangeano:

$$
\mathcal{L}=\sum_{t=0}^{\infty} \delta^{t}\left[y_{t}^{\prime} Q y_{t}+i_{t}^{\prime} R i_{t}+2 \delta \mu_{t+1}^{\prime}\left(A y_{t}+B i_{t}-y_{t+1}\right)\right]
$$

onde $\mu_{t}$ é o multiplicador de Lagrange.

A seguir, escreve-se as condições de primeira ordem para $i_{t}$ e $y_{t}$. A condição de primeira ordem para $y_{t}$ não é trivial, já que aparecem $y_{t}$ e $y_{t+1}$ na equação. Os passos para se obter as condições de primeira ordem são mostrados no apêndice B. O resultado final é mostrado a seguir:

$$
\begin{array}{r}
\frac{\partial \mathcal{L}}{\partial i_{t}}=2 i_{t}^{\prime} R+2 \delta \mu_{t+1}^{\prime} B=0 \\
\frac{\partial \mathcal{L}}{\partial y_{t}}=2 y_{t}^{\prime} Q+2 \delta \mu_{t+1}^{\prime} A-2 \mu_{t}^{\prime}=0
\end{array}
$$

Então:

$$
\begin{gathered}
i_{t}=-R^{-1} \delta B^{\prime} \mu_{t+1} \\
\delta A^{\prime} \mu_{t+1}=\mu_{t}-Q y_{t}
\end{gathered}
$$

Substitui-se a expressão para $i_{t}$ na dinâmica do sistema 5.32 :

$$
y_{t+1}=A y_{t}-\delta B R^{-1} B^{\prime} \mu_{t+1}
$$

A seguir junta-se essa equação com a condição de primeira ordem para $y_{t}$, ou seja, 
com:

$$
y_{t+1}=A y_{t}-\delta B R^{-1} B^{\prime} \mu_{t+1}
$$

e

$$
\delta A^{\prime} \mu_{t+1}=\mu_{t}-Q y_{t}
$$

pode-se montar o sistema de equações:

$$
\left[\begin{array}{cc}
I & \delta B R^{-1} B^{\prime} \\
0 & \delta A^{\prime}
\end{array}\right]\left[\begin{array}{l}
y_{t+1} \\
\mu_{t+1}
\end{array}\right]=\left[\begin{array}{cc}
A & 0 \\
-Q & I
\end{array}\right]\left[\begin{array}{l}
y_{t} \\
\mu_{t}
\end{array}\right]
$$

Por fim, é preciso reescrever o sistema de equações para que seja possível a aplicação do método de Blanchard e Kann. Para isso, decompõe-se o multiplicador de Lagrange em uma parcela predeterminada e uma parcela antecipativa. Seja:

$$
\mu_{t}=\left[\begin{array}{l}
\mu_{z t} \\
\mu_{x t}
\end{array}\right]
$$

onde $\mu_{z t}$ é a parcela associada às variáveis autorregressivas e $\mu_{x t}$ é associada às variáveis antecipativas.

Assim, chega-se a:

$$
\left[\begin{array}{cc}
I & \delta B R^{-1} B^{\prime} \\
0 & \delta A^{\prime}
\end{array}\right]\left[\begin{array}{c}
z_{t+1} \\
x_{t+1} \\
\mu_{z t+1} \\
\mu_{x t+1}
\end{array}\right]=\left[\begin{array}{cc}
A & 0 \\
-Q & I
\end{array}\right]\left[\begin{array}{l}
z_{t} \\
x_{t} \\
\mu_{z t} \\
\mu_{x t}
\end{array}\right]
$$

Define-se:

$$
H_{a u x}=\left[\begin{array}{cc}
I & \delta B R^{-1} B^{\prime} \\
0 & \delta A^{\prime}
\end{array}\right]
$$




$$
D_{\text {aux }}=\left[\begin{array}{cc}
A & 0 \\
-Q & I
\end{array}\right]
$$

As linhas da variável de estado são trocadas de modo que as variáveis autorregressivas e antecipativas possam ser separadas. Em consequência as colunas das matrizes $H_{a u x}$ e $D_{a u x}$ também são trocadas. Escreve-se portanto:

$$
H_{a u x}\left[\begin{array}{c}
z_{t+1} \\
x_{t+1} \\
\mu_{z t+1} \\
\mu_{x t+1}
\end{array}\right] \Rightarrow H\left[\begin{array}{c}
z_{t+1} \\
\mu_{z t+1} \\
x_{t+1} \\
\mu_{x t+1}
\end{array}\right]
$$

$\mathrm{E}$

$$
D_{a u x}\left[\begin{array}{c}
z_{t} \\
x_{t} \\
\mu_{z t} \\
\mu_{x t}
\end{array}\right] \Rightarrow D\left[\begin{array}{c}
z_{t} \\
\mu_{z t} \\
x_{t} \\
\mu_{x t}
\end{array}\right]
$$

Em seguida define-se os novos vetores de variáveis predeterminadas e antecipativas como:

$$
F_{t}=\left[\begin{array}{c}
z_{t} \\
\mu_{z t}
\end{array}\right] \text { e } f_{t}=\left[\begin{array}{c}
x_{t} \\
\mu_{x t}
\end{array}\right]
$$

o que leva finalmente à:

$$
H\left[\begin{array}{c}
F_{t+1} \\
f_{t+1}
\end{array}\right]=D\left[\begin{array}{c}
F_{t} \\
f_{t}
\end{array}\right]
$$

Aplicando o método de Blanchard (1983) para resolver a equação de diferença com variáveis antecipativas, obtém-se a solução para as variáveis $F_{t}$ e $f_{t}$. Assim, conforme mostrado anteriormente, fica:

$$
\begin{gathered}
F_{t+1}=M F_{t} \\
f_{t}=Z_{21} Z_{11}^{-1} F_{t}
\end{gathered}
$$


Com a condição inicial $F_{0}=\left[\begin{array}{c}z_{0} \\ \mu_{z 0}\end{array}\right]=\left[\begin{array}{c}z_{0} \\ 0\end{array}\right]$ Pode-se ainda reescrever a solução em função das variáveis iniciais e dos multiplicadores de Lagrange, o que leva a:

$$
\begin{gathered}
{\left[\begin{array}{l}
z_{t+1} \\
\mu_{z t+1}
\end{array}\right]=M\left[\begin{array}{l}
z_{t} \\
\mu_{z t}
\end{array}\right]} \\
{\left[\begin{array}{c}
x_{t} \\
\mu_{x t}
\end{array}\right]=Z_{21} Z_{11}^{-1}\left[\begin{array}{l}
z_{t} \\
\mu_{z t}
\end{array}\right]}
\end{gathered}
$$

O controle ótimo fica definido pela condição de primeira ordem:

$$
i_{t}=-R^{-1} \delta B^{\prime} \mu_{t+1}=-R^{-1} \delta B^{\prime}\left[\begin{array}{l}
\mu_{z t+1} \\
\mu_{x t+1}
\end{array}\right]
$$

Resumidamente, o problema de controle pode ser resolvido com os seguintes passos:

(a) Definições

Custo do período:

$$
L_{t}=y_{t}^{\prime} Q y_{t}+i_{t}^{\prime} R i_{t}
$$

Custo total:

$$
J=\left[\sum_{t=0}^{\infty} \delta^{t} L_{t}\right]
$$

Modelo:

$$
y_{t+1}=A y_{t}+B i_{t}+C \xi_{t+1}
$$

(b) Montar o sistema de equações:

$$
\left[\begin{array}{cc}
I & \delta B R^{-1} B^{\prime} \\
0 & \delta A^{\prime}
\end{array}\right]\left[\begin{array}{l}
y_{t+1} \\
\mu_{t+1}
\end{array}\right]=\left[\begin{array}{cc}
A & 0 \\
-Q & I
\end{array}\right]\left[\begin{array}{l}
y_{t} \\
\mu_{t}
\end{array}\right]
$$


(c) Decompor e agrupar os termos antecipativos a autorregressivos:

$$
\begin{gathered}
F_{t}=\left[\begin{array}{c}
z_{t} \\
\mu_{z t}
\end{array}\right] \text { e } f_{t}=\left[\begin{array}{l}
x_{t} \\
\mu_{x t}
\end{array}\right] \\
H\left[\begin{array}{c}
F_{t+1} \\
f_{t+1}
\end{array}\right]=D\left[\begin{array}{c}
F_{t} \\
f_{t}
\end{array}\right]
\end{gathered}
$$

(d) Resolver a equação de diferenças:

Aplica-se a decomposição QZ nas matrizes $H$ e $D$ e utiliza-se a condição de transversalidade. No fim a solução é dada por:

$$
\begin{gathered}
F_{t+1}=Z_{11} S_{11}^{-1} T_{11} Z_{11}^{-1} F_{t} \\
f_{t}=Z_{21} Z_{11}^{-1} F_{t}
\end{gathered}
$$

(e) Calcular o controle ótimo:

$$
i_{t}=-R^{-1} \delta B^{\prime} \mu_{t+1}=-R^{-1} \delta B^{\prime}\left[\begin{array}{l}
\mu_{z t+1} \\
\mu_{x t+1}
\end{array}\right]
$$

\subsubsection{Método do Ponto de Sela Recursivo}

O problema de minimizar a função custo (5.31) sujeito à dinâmica 5.32 pode ser transformado em um problema com a mesma forma LQR padrão, conforme mostrado por Marcet e Marimon (1994). Primeiramente, deve-se reescrever a equação (5.32) na seguinte forma:

$$
z_{t+1}=A_{11} z_{t}+A_{12} x_{t}+B_{1} i_{t}+C \xi_{t+1}
$$

$$
H x_{t+1}=A_{21} z_{t}+A_{22} x_{t}+B_{2} i_{t}
$$


onde as matrizes $A$ e $B$ da equação 5.32 foram particionadas de acordo com $z_{t}$ e $x_{t}$ :

$$
A=\left[\begin{array}{cc}
A_{11} & A_{12} \\
A_{21} & A_{22}
\end{array}\right], B=\left[\begin{array}{c}
B_{1} \\
B_{2}
\end{array}\right]
$$

Em seguida, o Lagrangeano mostrado na equação (5.34) pode ser reescrito como:

$$
\mathcal{L}=E\left[\sum_{t=0}^{\infty} \delta^{t}\left\{\begin{array}{c}
L_{t}+\rho_{1, t}^{T}\left(H x_{t+1}-A_{21} z_{t}-A_{22} x_{t}-B_{2} i_{t}\right)+ \\
\rho_{2, t+1}^{T}\left(X_{t+1}-A_{11} z_{t}-A_{12} x_{t}-C \xi_{t+1}\right)
\end{array}\right\} \mid t=0\right]
$$

onde o multiplicador de Lagrange $\mu$ foi decomposto nas componentes $\rho_{1}$ e $\rho_{2}$.

Em seguida, dada a condição inicial do multiplicador de Lagrange $\rho_{1,-1}=0$, pode-se escrever:

$$
\sum_{t=0}^{\infty} \delta^{t} \rho_{1, t} H x_{t+1}=\sum_{t=0}^{\infty} \delta^{t-1} \rho_{1, t-1} H x_{t}
$$

Usando a a propriedade acima, o lagrangeano pode ser reescrito como:

$$
\mathcal{L}=E\left[\sum_{t=0}^{\infty} \delta^{t}\left\{L_{t}+\begin{array}{c}
\rho_{1, t}^{T}\left(-A_{21} z_{t}-A_{22} x_{t}-B_{2} i_{t}\right)+\frac{1}{\delta} \rho_{1, t-1}^{T} H x_{t}+ \\
+\rho_{2, t+1}^{T}\left(z_{t+1}-A_{11} z_{t}-A_{12} x_{t}-C \xi_{t+1}\right)
\end{array}\right\} \mid t=0\right]
$$

O controle ótimo é a sequencia $i_{t}$ que minimiza o lagrangeano 5.50 . Entretanto, pode-se dividir o problema de um modo que a otimização se torne mais simples. Assim, o termo que aparece junto ao multiplicador $\rho_{2, t+1}^{T}$ é retirado do lagrangeano, o que permite a construção de um lagrangeano modificado, conforme apresentado pela equação (5.51). Além disso, como o multiplicador remanescente aparece em dois termos com uma defasagem no tempo, introduz-se um novo controle $\gamma_{1, t}^{T}$ e uma nova variável predeterminada $\rho_{1, t-1}^{T}$.

$$
\tilde{L}_{t}\left(z_{t}, \rho_{t-1} ; x_{t}, i_{t}, \gamma_{t}\right)=L_{t}+\gamma_{1, t}^{T}\left(-A_{21} z_{t}-A_{22} x_{t}-B_{2} i_{t}\right)+\delta^{-1} \rho_{1, t-1}^{T} H x_{t}
$$

O controle $\gamma_{1, t}^{T}$ é obviamente igual a $\rho_{1, t}^{T}$. Essa condição é incluída como uma nova 
equação de transição:

$$
\rho_{1, t}=\gamma_{1, t}
$$

Conforme Marcet e Marimon (1994), a dualidade do Lagrangeano que permite transformar um problema de minimização em um problema de ponto de sela:

$$
\min _{i_{t}} \mathcal{L}=\max _{\rho_{1, t}} \min _{i_{t}, x_{t}} E\left[\sum_{t=0}^{\infty} \delta^{t} \tilde{L}_{t}\right]
$$

onde esse problema de ponto de sela é restrito à dinâmica (5.47), à equação de transição (5.52) e à condição inicial $\rho_{1,-1}=0$.

Define-se então as novas variáveis:

$$
\tilde{z}_{t}=\left[\begin{array}{c}
z_{t} \\
\rho_{1, t}
\end{array}\right], \tilde{i_{t}}=\left[\begin{array}{c}
x_{t} \\
i_{t} \\
\gamma_{t}
\end{array}\right]
$$

E também define-se também as matrizes $\tilde{A}, \tilde{B}, \tilde{C}$ e $\tilde{W}$ :

$$
\begin{gathered}
\tilde{A}=\left[\begin{array}{cc}
A_{11} & 0 \\
0 & 0
\end{array}\right], \tilde{B}=\left[\begin{array}{ccc}
A_{12} & 0 & 0 \\
0 & 0 & I
\end{array}\right], \tilde{C}=\left[\begin{array}{l}
C \\
0
\end{array}\right] \\
\tilde{W}=\left[\begin{array}{ccccc}
Q_{11} & 0 & Q_{12}^{T} & 0 & -A_{21}^{T} \\
0 & 0 & \delta^{-1} H & 0 & 0 \\
Q_{12} & \delta^{-1} H & Q_{22} & 0 & -A_{22}^{T} \\
0 & 0 & 0 & R & -B_{2}^{T} \\
-A_{21} & 0 & -A_{22} & -B_{2} & 0
\end{array}\right]
\end{gathered}
$$

Assim, o sistema pode ser reescrito como:

$$
\tilde{z}_{t+1}=\tilde{A} \tilde{z}_{t}+\tilde{B} \tilde{i}_{t}+\tilde{C} \epsilon_{t+1}
$$




$$
\tilde{L}_{t}=\frac{1}{2}\left[\begin{array}{c}
\tilde{z}_{t} \\
\tilde{i}_{t}
\end{array}\right]^{T} \tilde{W}\left[\begin{array}{c}
\tilde{z}_{t} \\
\tilde{i}_{t}
\end{array}\right]
$$

O problema (5.53) sujeito à (5.57) e à condição inicial $\tilde{z}_{0}$ é isomórfico ao problema do LQR, com a única diferença que se trata de um problema de ponto de sela. Entretanto, as condições de primeira ordem do problema do ponto de sela são as mesmas do problema do LQR.

Para encontrar a solução, primeiramente se reescreve a função custo na forma padrão:

$$
\tilde{L}_{t}=\frac{1}{2}\left\{\tilde{z}_{t}^{T} \tilde{Q} \tilde{z}_{t}+2 \tilde{z}_{t}^{T} N \tilde{i}_{t}+\tilde{i}_{t}^{T} \tilde{R}_{i}\right\}
$$

onde as matrizes $\tilde{Q}, \tilde{R}$ e $N$ são definidas como:

$$
\tilde{Q}=\left[\begin{array}{cc}
Q_{11} & 0 \\
0 & 0
\end{array}\right], N=\left[\begin{array}{ccc}
0 & 0 & -A_{21}^{T} \\
\delta^{-1} H & 0 & 0
\end{array}\right], \tilde{R}=\left[\begin{array}{ccc}
Q_{22} & 0 & -A_{22}^{T} \\
0 & R & -B_{2}^{T} \\
-A_{22} & -B_{2} & 0
\end{array}\right]
$$

Assim, segue que a solução para $\tilde{i}_{t}^{*}$ pode ser escrita como:

$$
\tilde{i}_{t}^{*}=-F \tilde{z}_{t}
$$

onde

$$
F=\left(\tilde{R}+\delta \tilde{B}^{T} P \tilde{B}\right)^{-1}\left(N^{T}+\delta \tilde{B}^{T} P \tilde{A}\right)
$$

A matriz $P$ é encontrada resolvendo a equação de Riccati:

$$
P=\tilde{Q}+\delta \tilde{A}^{T} P \tilde{A}-\left(N^{T}+\delta \tilde{B}^{T} P \tilde{A}\right)^{T}\left(\tilde{R}+\delta \tilde{B}^{T} P \tilde{B}\right)^{-1}\left(N^{T}+\delta \tilde{B}^{T} P \tilde{A}\right)
$$

Por fim, a matriz F gera a solução não apenas para o problema do ponto de sela, mas também para o problema original. Basta, portanto, efetuar uma mudança de 
variáveis e retornar para as variáveis do problema original. A solução final fica:

$$
\begin{gathered}
{\left[\begin{array}{c}
z_{t+1} \\
\rho_{t+1}
\end{array}\right]=(\tilde{A}-\tilde{B} F)\left[\begin{array}{l}
z_{t} \\
\rho_{t}
\end{array}\right]+\tilde{C} \xi_{t+1}} \\
{\left[\begin{array}{c}
x_{t} \\
i_{t} \\
\gamma_{t}
\end{array}\right]=-F\left[\begin{array}{l}
z_{t} \\
\rho_{t}
\end{array}\right]}
\end{gathered}
$$

Em resumo, o problema original é reformulado pela incorporação do bloco de equações para as variáveis antecipativas, de modo que o problema do ponto de sela se torne recursivo e isomórfico ao problema do LQR.

O método do ponto de sela recursivo e o método do Lagrangeano não necessariamente levam aos mesmos resultados, uma vez que a condição de transversalidade é diferente. A figura (5.4) mostra comparação entre as simulações numéricas de cada caso.

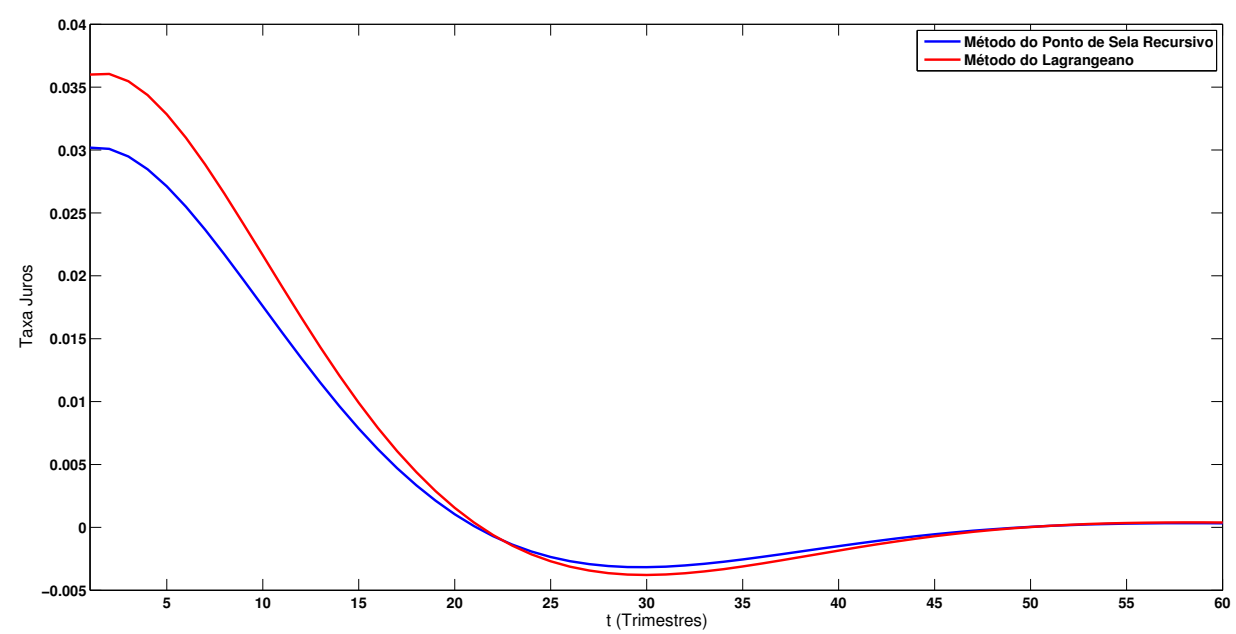

Figura 5.4: Controle Ótimo para os dois métodos apresentados 


\section{Capítulo 6}

\section{Resultados das Simulações Numéricas}

\subsection{Introdução}

No capítulo 5, foram apresentadas as políticas de controle ótimo para o modelo keynesiano, definido pela equação (3.3), e para o modelo novo keynesiano, definido pela equação (3.11). Os parâmetros dos modelos foram estimado conforme mostrado no capítulo 4. Portanto, o objetivo deste capítulo é a determinação numérica das políticas de controle ótimo. Isso permite a comparação entre as políticas ótimas e as políticas efetivamente empregadas.

Inicialmente, serão reapresentados os modelos utilizados, já com os respectivos parâmetros estimados. Em seguida, é feita uma discussão sobre os pesos adequados para a função custo. Por fim, as políticas ótimas são calculadas para algumas condições iniciais de interesse. 


\subsection{Revisão dos modelos estimados}

O modelo keynesiano estimado é dado pelo sistema de equações abaixo, arredondando os parâmetros para a terceira casa decimal:

$$
\begin{aligned}
& \pi_{t+1}=0.425 \pi_{t}+0.607 y_{t}+\epsilon_{\pi t} \\
& h_{t+1}=0.705 h_{t}-0.038\left(i_{t}-\pi_{t}\right)+\epsilon_{h t}
\end{aligned}
$$

Os autovalores do sistema são $\lambda_{1}=0.358$ e $\lambda_{2}=0.772$, ou seja, como ambos os autovalores possuem módulo menor que um, o sistema é estável no sentido de Lyapunov. Assim, os sistema retorna ao ponto de equilíbrio após sofrer um choque inicial. Assim, o papel da variável de controle é fazer com que o sistema retorne ao ponto de equilíbrio de um modo mais rápido do que se fosse deixado sem controle.

Já o modelo novo-keynesiano estimado é escrito como:

$$
\begin{aligned}
\pi_{t} & =0.873 E\left[\pi_{t+1} \mid t\right]-0.295 y_{t}+\epsilon_{\pi t} \\
E\left[h_{t+1} \mid t\right] & =h_{t}+0.009\left(i_{t}-E\left[\pi_{t+1} \mid t\right]\right)+\epsilon_{y t} \\
\epsilon_{\pi t+1} & =-0.166 \epsilon_{\pi t}+\varsigma_{\pi t+1} \\
\epsilon_{h t+1} & =0.087 \epsilon_{h t}+\varsigma_{h t+1}
\end{aligned}
$$

A decomposição de Schur aplicada às matrizes $A$ e $H$, leva aos seguintes autovalores generalizados:

$$
\begin{aligned}
& \lambda_{1}=1.048-0.031 \iota \\
& \lambda_{2}=1.048+0.031 \iota \\
& \lambda_{3}=-0.166 \\
& \lambda_{4}=0.087
\end{aligned}
$$

Assim, há dois autovalores com norma maior de um e dois autovalores com norma 
menor que um. Desta forma, as condições do teorema de Blanchard e Kahn (1980) são satisfeitas e o sistema admite solução única.

\subsection{Revisão da função custo}

A função custo pode ser escrita como:

$$
J=E\left[\sum_{t=0}^{\infty} \delta^{t} L_{t}\right]
$$

onde $\delta$ é o fator de desconto e $L_{t}$ é o custo intertemporal:

$$
L_{t}=y_{t}^{\prime} Q y_{t}+i_{t}^{\prime} R i_{t}
$$

A rigor, a variável de estado $y_{t}$ não é a mesma para os dois modelos, pois cada um tem um conjunto de variáveis de estado diferente. Assim, para uniformizar os resultados, aplica-se pesos similares para as variáveis comuns aos dois modelos.

Para o modelo keynesiano, a variável de estado y é um vetor com dois componentes: a inflação $\pi$ e o hiato do produto $h$. Assim a matriz $Q$ da função custo possui ordem $2 x 2$. Escolhe-se os parâmetros de modo que o custo associado a inflação seja maior que o custo associado ao hiato do produto. Não será incluído custo para o efeito cruzado entre inflação e hiato do produto. Assim:

$$
Q=\left[\begin{array}{cc}
1 & 0 \\
0 & 0.1
\end{array}\right]
$$

Já para o modelo novo keynesiano há 4 variáveis de estado, o que faz com que a matriz $Q$ possua ordem $4 x 4$. Duas das variáveis de estado são as variáveis antecipativas, que são os choques autorregressivos. A princípio não faz sentido atribuir um custo para as variáveis que são choques no modelo. As outras duas variáveis são a inflação e o hiato do produto, para as quais se emprega o mesmo peso usado no modelo keynesiano, 
ou seja:

$$
Q=\left[\begin{array}{llll}
0 & 0 & 0 & 0 \\
0 & 0 & 0 & 0 \\
0 & 0 & 1 & 0 \\
0 & 0 & 0 & 0.1
\end{array}\right]
$$

Um outro parâmetro da função custo é o peso do controle. Neste problema não há nenhuma restrição quanto a utilização das taxas de juros, então escolhe-se um peso relativamente baixo: $R=0.01$. A figura 6.1 apresenta o efeito do valor de $R$ no controle ótimo. Quanto maior o peso de $R$, maior o custo do controle e, consequentemente, o controle ótimo atinge valores menores.

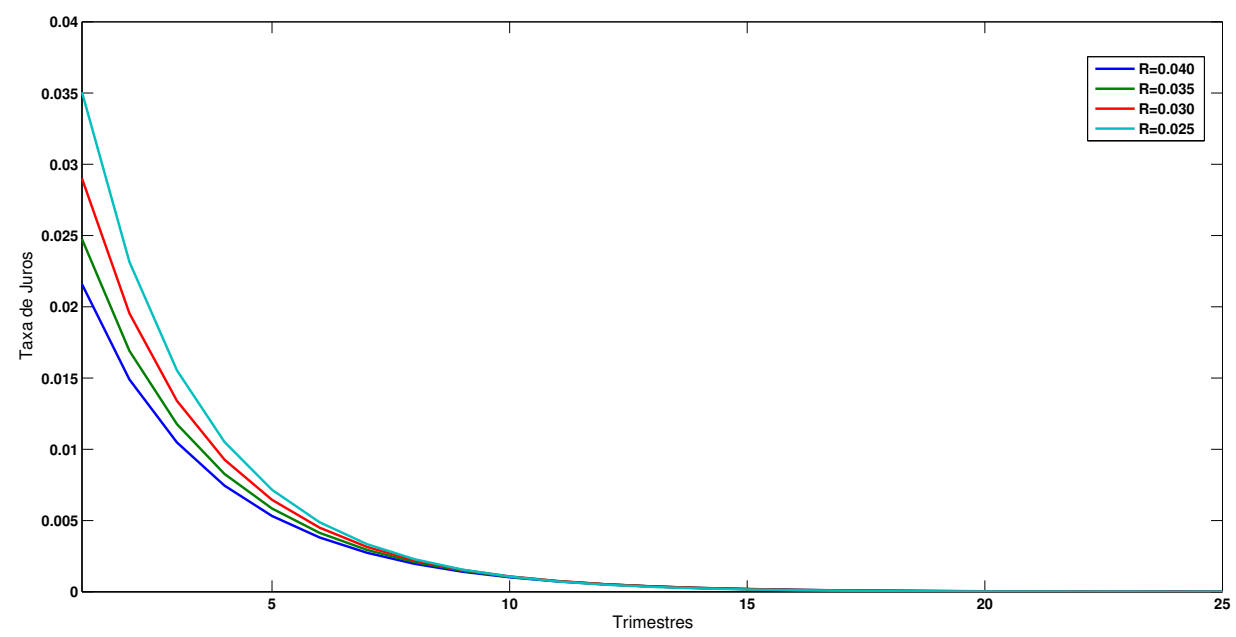

Figura 6.1: Política Ótima no modelo keynesiano em função de R

Por fim, falta definir o fator de desconto $\delta$. Como o mandato dos tomadores de decisão tem a duração de 4 anos (ou 16 trimestres), o fator de desconto é calibrado para que a soma dos descontos durante esses 16 período seja $75 \%$ da soma infinita. Ou seja:

$$
75 \% \frac{1}{1-\delta}=\frac{\delta^{16}-1}{\delta-1}
$$

Resolvendo a equação, obtém-se $\delta=0.917$. A figura 6.2 apresenta o controle ótimo no modelo keynesiano para outros valores do fator de desconto. Observa-se que, quanto 
maior o fator de desconto, ou seja, quanto maior a importância dada aos períodos futuros, maior deve ser o controle aplicado.

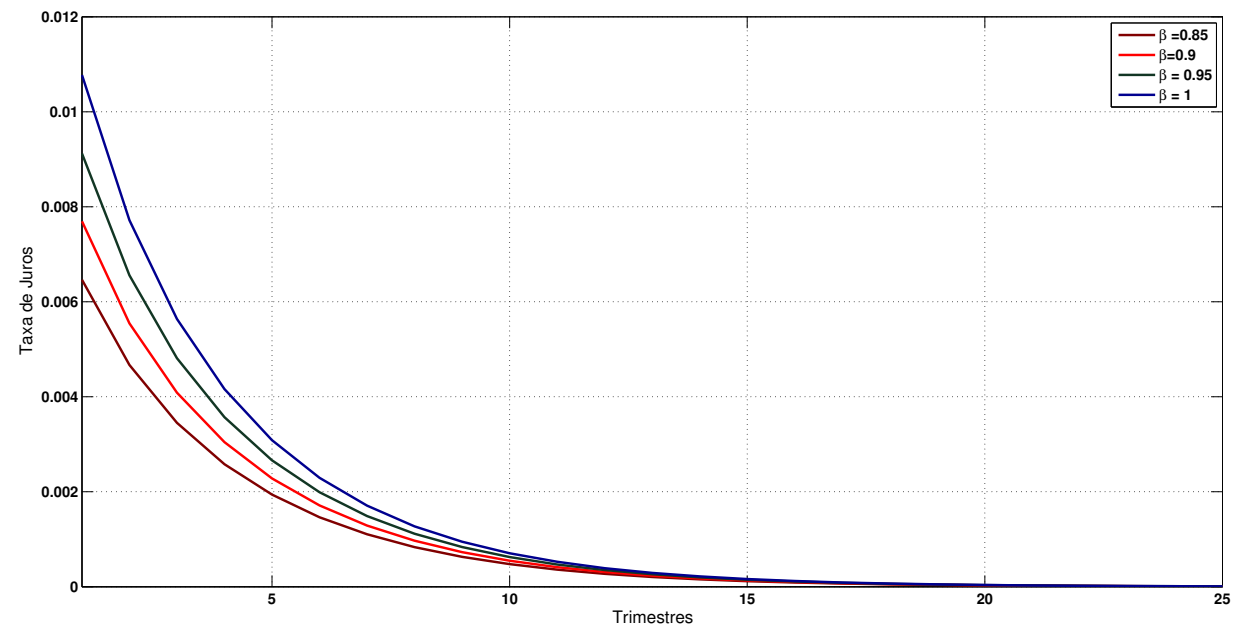

Figura 6.2: Efeito do fator de desconto no controle ótimo

\subsection{Análise de cenários para condições iniciais}

Uma vez definido os parâmetros da função custo, o próximo passo consiste em analisar a resposta à condição inicial. No caso do modelo keynesiano, a condição inicial é dada pela inflação e hiato do produto. Já no modelo novo keynesiano, a condição inicial é dada pelos choque no hiato do produto e pelo choque inflacionário, que são as variáveis antecipativas do modelo. Assim, o objetivo desta seção é determinar a solução ótima para algumas condições iniciais de interesse:

- Expectativa de inflação acima da meta e produção econômica em forte expansão (hiato do produto positivo). Nesse cenário, a expansão da atividade econômica provoca a redução no desemprego e a pressão por salários reais maiores para os trabalhadores ao mesmo tempo que a capacidade de produção se torna um limitante para a oferta de bens e serviços, pressionando o aumento da inflação.

- Expectativa de inflação baixa e produção econômica estagnada. Esse cenário se caracteriza por altas taxas de desemprego e uma grande capacidade ociosa na 
indústria. A expectativa de inflação baixa e incertezas quando ao emprego, fazem com que as famílias reduzam o consumo e aumentem as economias.

O primeiro dos cenários é mostrado na figura 6.3. Neste caso há um choque inflacionário juntamente com um aquecimento da economia. Uma vez que o governo registra a inflação acima da meta, as taxas de juros são elevadas em mais de 1\%. Entretanto, a política monetária não tem efeito imediato, e o aquecimento da atividade econômica provoca um aumento ainda maior da inflação. A partir do segundo período, as taxas de juros mais altas começam a surtir efeito e a inflação começa a cair. Em seguida, o governo começa a diminuir gradativamente a taxa de juros até chegar a um ponto de equilíbrio.

O segundo cenário, mostrado na figura 6.4, apresenta uma situação de atividade econômica e inflação baixas. Nesse caso, a resposta do governo segundo o modelo deveria ser uma redução na taxa de juros de pouco mais de 1\%. Essa política permitiria um incentivo à atividade econômica com a posterior retomada da inflação ao centro da meta.

Taxa de Juros

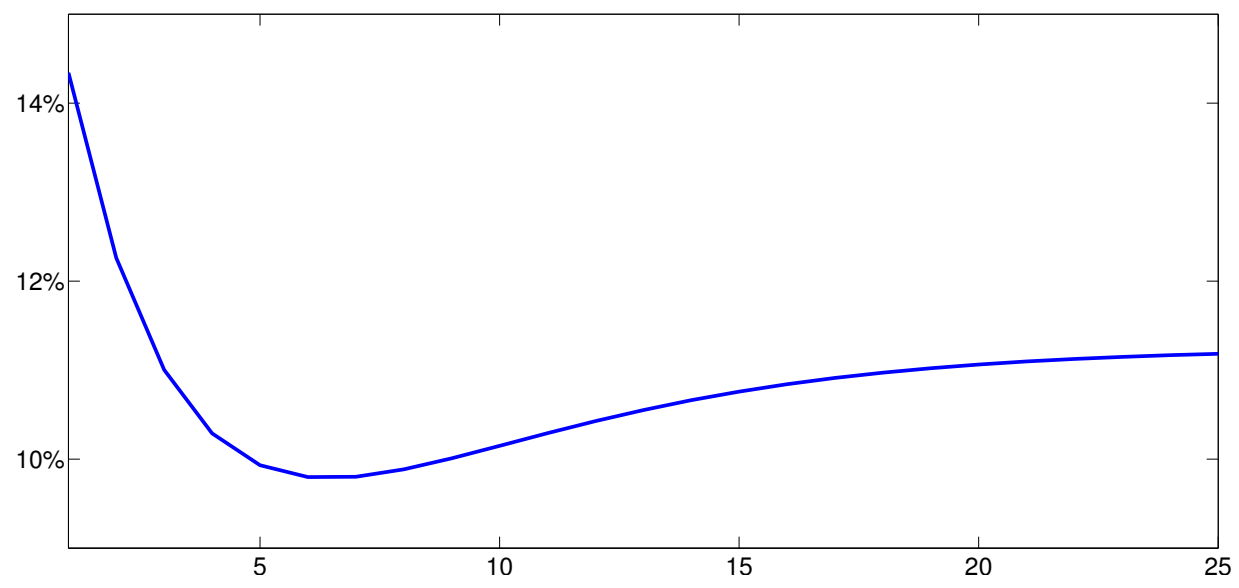

Figura 6.3: Resultado da simulação para o cenário de inflação inicial alta 


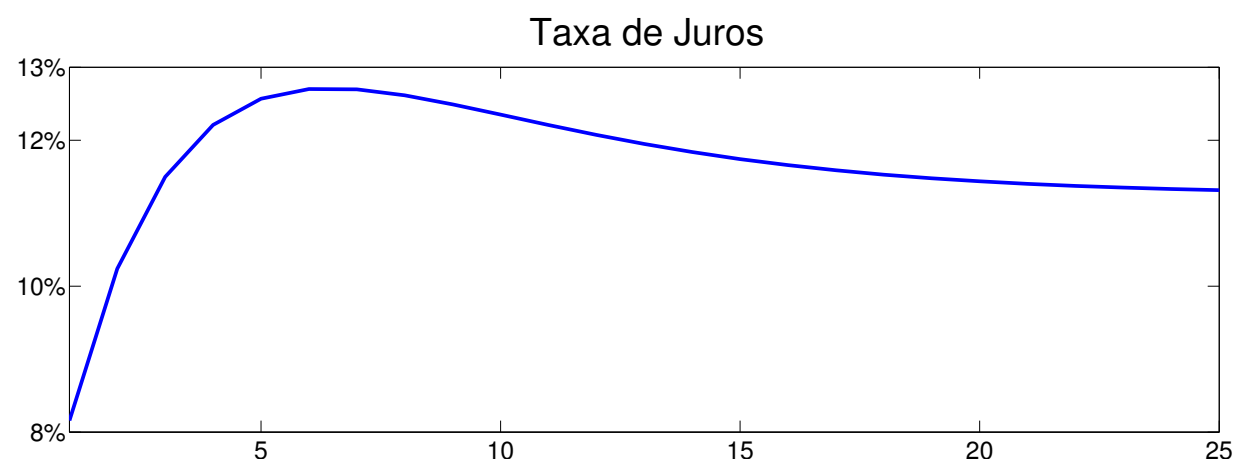

Figura 6.4: Resultado da simulação para o cenário de inflação inicial baixa

\subsection{Comparação entre a política ótima e a política implementada no Brasil}

O objetivo desta seção é comparar a política monetária sugerida pelo modelo com a política implementada pelo governo. O período entre 2008 e 2009 foi escolhido pois apresenta características singulares, como o aumento da inflação juntamente com um forte crescimento econômico no começo de 2008, seguido de um período recessivo que se estendeu dos últimos meses de 2008 ao início de 2009.

Em março de 2008 a taxa Selic estava em 11,25\% e a expectativa de inflação estava próxima à meta de inflação de $4.5 \%$. Nos meses seguintes, a expectativa de inflação começou a subir, chegando a atingir 5,23\% em junho. Nesse momento a taxa selic estava $12,25 \%$, e foi elevada continuamente até atingir $13,75 \%$ em setembro daquele ano. A taxa foi mantida nesse patamar até janeiro de 2009, quando a expectativa de inflação já estava próxima da meta e a economia já dava amplos sinais de estar entrando em recessão (hiato do produto negativo). Mesmo assim, o governo reduziu levemente a Selic para 12,75\%, ainda muito acima dos valores registrados em março de 2008. Entre janeiro e julho de 2009, o governo reduziu a taxa Selic para 8,75\%, quando a expectativa de inflação já se encontrava em 4,10\%, bem abaixo da meta.

Conclui-se que o governo brasileiro optou por uma política de movimentos graduais na taxa de juros. Entretanto, conforme verificado nas simulações, tal política não é 
ótima. Os resultados da pesquisa desenvolvida neste trabalho sugerem que a aplicação de choques na política monetária gera um resultado melhor que a modificação gradual das taxas de juros. Utilizando o cenário de junho de 2008, o modelo sugeriria um aumento próximo de $3 \%$ na taxa selic. O efeito desse salto na taxa de juros seria manter a expectativa de inflação perto da meta e evitar o superaquecimento da economia visto nos meses seguintes. Isso permitiria ao governo baixar rapidamente as taxas de juros até o mês de setembro, quando o cenário já tinha mudado totalmente.

Um dos problemas do gradualismo adotado na política monetária é que os ciclos econômicos podem mudar de modo rápido, o que faz com que a política seja aplicada em um momento inadequado. Assim, a política monetária aplicada em 2008 acabou por aumentar os efeitos dos ciclos econômicos, o que se evidenciou no resultado do produto interno bruto que apresentou uma queda acumulada de $6 \%$ entre julho e dezembro de 2008. 


\section{Capítulo 7}

\section{Conclusão}

O objetivo deste trabalho é apresentar métodos para a otimização da política monetária. Para isso, é necessário pesquisar um modelo que reflita a dinâmica econômica, estimar os parâmetros desse modelo e definir uma função custo para ser minimizada.

A pesquisa sobre opções de modelos macroeconômicos revelou um pouco sobre a evolução do pensamento econômico e sobre a própria evolução das técnicas de controle. Os trabalhos iniciais imaginavam a economia como um sistema evoluindo mecanicamente de um estado para outro, e o caminho para achar políticas ótimas cada vez mais confiáveis seria pela procura por modelo mais complexos, explorando não-linearidades entre as variáveis.

Entretanto, o desenvolvimento de novas teoria mostrou que o resultado desses trabalhos iniciais eram inválidos. Na verdade, os sistemas econômicos são muitos mais complexos do que qualquer modelos recursivos disponíveis na época. Ao invés de um modelo dinâmico, surgiram os modelos de equilíbrio que representam o equilíbrio formado pela decisão ótima de cada agente econômico. O que caracteriza esses modelos é a hipótese das expectativas racionais, assim ao invés de olhar para o passado, a melhor explicação para o presente viria da observação das expectativas para o futuro.

Enquanto os antigos modelos keynesianos possuíam uma formulação recursiva, permitindo a utilização de programação dinâmica para encontrar a política ótima, os novos modelos, entre os quais estão os novos keynesianos, não possuíam essa formulação re- 
cursiva. Assim, o controle ótimo não poderia ser encontrado diretamente.

A solução para o problema de controle ótimo em um modelo com expectativas racionais passa pela utilização ou do método do Lagrangeano ou pelo método do ponto de sela recursivo. O primeiro utiliza condições de primeira ordem para incluir a variável de controle entre as variáveis de estado e depois utiliza o método para resolver um modelo com expectativas racionais comum. São adicionadas condições de transversalidade para garantir a existência de uma solução. Já o segundo método parte do método dos multiplicadores de Lagrange e explora a dualidade do lagrangiano para reescrever um problema de minimização como um problema de ponto de sela, restrito à uma equação recursiva. Esse problema pode ser resolvido usando uma mudança de variáveis que permite reescrever o problema como um LQR comum.

Também foi apresentado o problema de estimação de variáveis não-observáveis e estimação de parâmetros. O primeiro foi resolvido pelo método de Harvey-Clark e pelo filtro de Hodrick-Prescott, com ambos os métodos gerando resultados numéricos similares. Já o problema de estimação de parâmetros foi resolvido pelo OLS para o modelo keynesiano e pelo GMM para o modelo novo keynesiano. Como o modelo adotado foi muito simplificado, com apenas 4 variáveis de estado, os resultados de parâmetros estimados não tiveram significância estatística elevada, pois há muitas outras variáveis interferindo que deveriam ter sido consideradas. Entretanto, como o objetivo do trabalho era considerar a parte de política ótima em um modelo com poucas variáveis para que fosse possível estudar as relações fundamentais, o problema da significância estatística foi desconsiderado.

Em seguida, com os valores estimados para os parâmetros do modelo e as políticas monetárias ótimas analiticamente determinada, foram realizadas varias simulações para testar o resultado da política ótima em cenários predeterminados. Depreende-se, das simulações analisadas, que a resposta ótima do governo sempre é na forma de um salto inicial nas taxas de juros, com um gradual retorno aos valores de equilíbrio. Entretanto, analisando a Política Monetária implementada pelo governo brasileiro nos últimos anos, 
percebe-se que têm prevalecido um movimento gradual, tanto no aumento quanto na diminuição, das taxas de juros. Conforme mostrado, esse tipo de política gradualista não é compatível com a política ótima simulada neste trabalho.

Por outro lado, a crítica que se faz a esse tipo de modelo é que os parâmetros permanecem constante durante todo o período. Essa hipótese pode ser verdadeira quando o intervalo de tempo analisado é de poucos anos. Entretanto, para analisar ciclos durantes décadas não se pode assumir um modelo invariante no tempo. Uma possibilidade seria a utilização de modelos com saltos markovianos, onde cada estado possui um conjunto de parâmetros fixos e é associado à determinado modo de operação da economia. O problema para a aplicação desses modelos com saltos na analise econômica brasileira é a limitação na série de dados para estimar os parâmetros do modelo. Fica como sugestão para pesquisa futura a utilização de modelos com saltos markovianos e, ainda mais simples, a utilização de modelos com mais variáveis de estado, incluindo outras variáveis relevantes, como a taxa de câmbio, o desemprego e os gastos do governo (política fiscal). 


\section{Apêndice A}

\section{Calculo Matricial}

Uma vez que os conceitos de cálculo matricial são bastante utilizados ao longo do trabalho, cabe relembrar algumas propriedades úteis.

$$
\begin{gathered}
\frac{\partial A^{T} x B}{\partial x}=A B^{T} \\
\frac{\partial A^{T} x^{T} B}{\partial x}=B A^{T} \\
\frac{\partial x^{T} A x}{\partial x}=\left(A+A^{T}\right) x \\
\frac{\partial A^{T} x x^{T} B}{\partial x}=x^{T}\left(A B^{T}+B A^{T}\right)
\end{gathered}
$$




\section{Apêndice B}

\section{Passos intermediários em equações}

\section{B.1 Condições de Primeira ordem da equação}

O problema consiste em calcular a condição de primeira ordem com respeito a $y_{t}$ para a equação:

$$
\mathcal{L}=\sum_{t=0}^{\infty} \delta^{t}\left[y_{t}^{\prime} Q y_{t}+i_{t}^{\prime} R i_{t}+2 \delta \mu_{t+1}^{\prime}\left(A y_{t}+B i_{t}-y_{t+1}\right)\right]
$$

Para facilitar a solução, é preciso reescrever o termo envolvendo $y_{t}$ e $y_{t+1}$ como:

$$
\mathcal{L}=\sum_{t=0}^{\infty}\left[\delta^{t+1} \mu_{t+1}^{\prime}\left(A y_{t}-y_{t+1}\right)\right]=\sum_{t=1}^{\infty}\left[\left(\delta^{t+1} \mu_{t+1}^{\prime} A-\delta^{t} \mu_{t}^{\prime}\right) y_{t}\right]+\delta \mu_{1} A y_{0}
$$

Assim:

$$
\frac{\partial \mathcal{L}}{\partial y_{t}}=2 y_{t}^{\prime} R+2\left(\delta \mu_{t+1}^{\prime} A-\mu_{t}^{\prime}\right)=0
$$




\section{Referências Bibliográficas}

Areosa, M. (2008). Combining hodrick-prescott filtering with a production function approach to estimate output gap. Working Papers Series 172, Central Bank of Brazil, Research Department.

Backus, D. e Driffill, J. (1986). The consistency of optimal policy in stochastic rational expectations models. CEPR Discussion Papers 124, C.E.P.R. Discussion Papers.

Blanchard, O. e Fischer, S. (1989). Lectures on Macroeconomics. MIT Press.

Blanchard, O. J. (1983). Methods of solution and simulation for dynamic rational expectations models. NBER Technical Working Papers 0028, National Bureau of Economic Research, Inc.

Blanchard, O. J. e Kahn, C. M. (1980). The solution of linear difference models under rational expectations. Econometrica, 48(5):1305-11.

Bonomo, M. A. e Brito, R. D. (2001). Regras monetárias e dinâmica macroeconômica no brasil: uma abordagem de expectativas racionais. Technical report, Central Bank of Brazil, Research Department.

Clarida, R.; Galí, J. e Gertler, M. (1999). The science of monetary policy: A new keynesian perspective. Journal of Economic Literature.

Cusinato, R.; Minella, A. e Junior, S. D. S. P. (2010). Output gap and gdp in brazil: a real-time data analysis. Working Papers Series 203, Central Bank of Brazil, Research Department. 
Gali, J.; Gertler, M. e David Lopez-Salido, J. (2005). Robustness of the estimates of the hybrid new keynesian phillips curve. Journal of Monetary Economics, 52(6):11071118.

Harvey, A. C. (1985). Trends and cycles in macroeconomic time series. Journal of Business \& Economic Statistics, 3(3):216-27.

Hodrick, R. J. e Prescott, E. C. (1997). Postwar u.s. business cycles: An empirical investigation. Journal of Money, Credit and Banking, 29(1):1-16.

Kin, C.-J. K. e Nelson, C. R. (1999). State-Space Models with Regime Switching: Classical and Gibbs-Sampling Approaches with Applications, volume 1. The MIT Press, 1 edição.

Kwakernaak, H. e Sivan, R. (1972). Linear Optimal Control Systems. John Wiley \& Sons, Inc., New York, NY, USA.

Kydland, F. e Prescott, E. C. (1982). Time to build and aggregate fluctuations.

Levine, P. e Currie, D. (1987). The design of feedback rules in linear stochastic rational expectations models. Journal of Economic Dynamics and Control, 11(1):1-28.

Lindé, J. (2001). Estimating new-keynesian phillips curves: A full information maximum likelihood approach. Working Paper Series 129, Sveriges Riksbank (Central Bank of Sweden).

Ljungqvist, L. e Sargent, T. J. (2000). Recursive Macroeconomic Theory. MIT Press, Cambridge, Mass. [u.a.].

Lucas, R. E. (1976). Econometric policy evaluation: A critique. Carnegie-Rochester Conference Series on Public Policy, 1(1):19-46.

Marcet, A. e Marimon, R. (1994). Recursive contracts. Economics Working Papers 337, Department of Economics and Business, Universitat Pompeu Fabra. 
Modigliani, F. (1977). The monetarist controversy; or, should we forsake stabilization policies? Economic Review, pp. 27-46.

Moessner, R. (2006). Optimal discretionary policy in rational expectations models with regime switching. Bank of England working papers 299, Bank of England.

Muth, J. F. (1961). Rational expectations and the theory of price movements. Econometrica, 29(3):315-335.

Neiss, K. e Nelson, E. (2002). Inflation dynamics, marginal cost, and the output gap: evidence from three countries. Proceedings.

Orphanides, A. e Wieland, V. (2000). Inflation zone targeting. European Economic Review, 44(7):1351-1387.

Oudiz, G. e Sachs, J. (1984). International policy coordination in dynamic macroeconomic models. NBER Working Papers 1417, National Bureau of Economic Research, Inc.

Pindyck, R. S. (1973). Optimal policies for economic stabilization. Econometrica, 41(3):529-560.

Rotemberg, J. J. e Woodford, M. (1998). An optimization-based econometric framework for the evaluation of monetary policy: Expanded version. Working Paper 233, National Bureau of Economic Research.

Sargent, T. e Wallace, N. (1974). Rational expectations and the theory of economic policy. Working Papers 29, Federal Reserve Bank of Minneapolis.

Simonsen, M. H. e Cysne, R. P. (2007). Macroeconomia. Editora Atlas, $3^{\text {a }}$ edição.

Sims, C. A. (2002). Solving linear rational expectations models. Computational Economics, 20(1-2):1-20.

Soderlind, P. (1999). Solution and estimation of re macromodels with optimal policy. European Economic Review, 43(4-6):813-823. 
Svensson, L. e Williams, N. (2005). Monetary policy with model uncertainty: Distribution forecast targeting. Working Paper 11733, National Bureau of Economic Research.

Svensson, L. E. e Williams, N. (2008). Optimal monetary policy under uncertainty in dsge models: A markov jump-linear-quadratic approach. Working Paper 13892, National Bureau of Economic Research.

Svensson, L. E. O. (1997). Inflation forecast targeting: Implementing and monitoring inflation targets. NBER Working Papers 5797, National Bureau of Economic Research, Inc.

Tustin, A. (1953). The Mechanism of Economic Systems. Harvard Univ. Press.

Woodford, M. (2003). Interest ES Prices: Foundations of a Theory of Monetary Policy. Princeton University Press. 